\title{
Correção Altimétrica do ASTER GDEM Através do Método de Superfícies de Compensação de Erros
}

\author{
ASTER GDEM Altimetric Correction Through the Error Compensation \\ Surface Method \\ Raphael e Silva Girão ${ }^{1}$ \\ Raúl Sánchez Vicens ${ }^{2}$ \\ Pedro José Farias Fernandes ${ }^{3}$
}

Recebido em fevereiro de 2019. Aprovado em abril de 2019.

\begin{abstract}
RESUMO
O objetivo do presente trabalho é avaliar e comparar a utilização de superfícies de compensação de erro geradas por interpolações determinísticas e geoestatísticas para o aumento da acurácia vertical dos MDEs oriundos do ASTER GDEM para o estado do Rio de Janeiro, utilizando como parâmetro de avaliação as diretrizes do Padrão de Exatidão Cartográfica dos Produtos Cartográficos Digitais (PEC-PCD), estabelecidas pela Norma da Especificação Técnica para Aquisição de Dados Geoespaciais Vetoriais de Defesa da Força Terrestre. As superfícies de compensação de erro se mostraram eficientes no aumento da acurácia vertical do MDE ASTER GDEM, consistindo em uma relevante alternativa para a correção altimétrica de MDEs, principalmente quando não se conhece detalhadamente a natureza e magnitude das fontes de erro dos mesmos. Ressalta-se também que a superfície de compensação de erro gerada por interpolação geoestatística foi a que obteve melhores resultados.
\end{abstract}

PALAVRAS-CHAVE: Correção de MDE. Interpolação. Geoestatística.

\begin{abstract}
The aim of the this paper is to evaluate and compare the use of error compensation surfaces generated by deterministic and geostatistical interpolations to increase the vertical accuracy of the DEMs from ASTER GDEM for Rio de Janeiro state, using as an evaluation parameter the guidelines of the Cartographic Accuracy Standard of Digital Cartographic
\end{abstract}

\footnotetext{
${ }^{1}$ Laboratório de Estudos Tectônicos - Faculdade de Geologia - Universidade do Estado do Rio de Janeiro, Rio de Janeiro, RJ, Brasil. E-mail: raphaelgirao@hotmail.com

${ }^{2}$ Laboratório de Geografia Física - Departamento de Geografia - Universidade Federal Fluminense, Niterói, RJ, Brasil. E-mail: rvicens@gmail.com

${ }^{3}$ Laboratório de Geografia Física - Departamento de Geografia - Universidade Federal Fluminense, Niterói, RJ, Brasil. E-mail: pj_fernandes@id.uff.br
} 
Products (PEC-PCD), established by the Technical Specification Standard for Acquisition of Geospatial Earth Defense Vector Data. The error compensation surfaces have been shown to be efficient in increasing the vertical accuracy of the ASTER GDEM DEM, consisting in a relevant alternative for the altimetric correction of DEMs, especially when the nature and magnitude of the sources of error are not well known. It is also emphasized that the error compensation surface generated by geostatistical interpolation was the one that obtained the best results

KEYWORDS: DEM Correction. Interpolation. Geostatistical.

\section{Introdução}

O conhecimento do relevo da superfície terrestre é de grande relevância para muitos segmentos da sociedade, uma vez que as atividades humanas se desenvolvem sobre tal superfície (LILLESAND, KIEFER e CHIPMAN, 2007). Por muito tempo, mapas topográficos têm sido usados para suporte aos inventários, levantamentos de recursos terrestres e análises geográficas de diferentes naturezas. Contudo, a produção de tais mapas por meio de métodos analógicos e mais convencionais é morosa, demandando uma significativa parcela de recursos e trabalho e, ainda assim, não atende de forma adequada a crescente necessidade de informações sobre o relevo e sua geomorfometria (BURROUGH e MCDONNELL, 1998).

A representação tradicional do relevo da superfície terrestre por meio de curvas de nível, pontos cotados e perfis topográficos não permitem análises numéricas computacionais eficientes, ágeis e precisas para diferentes problemas de análise geoespacial. Nesse contexto, os Modelos Digitais de Elevação (MDEs) são importantes recursos nos trabalhos de análise geoespacial e se tornaram fundamentais em estudos geomorfológicos e hidrológicos (TOUTIN, 2004; ASEELEN e SEIJMONSBERGEN, 2006; FRANKEL e DOLAN, 2007; BLASCHKE, 2010; ANDERS et al., 2011, VERHAGEN e DRAGUT, 2012; DRAGUT e EISANK, 2012; MUÑOZ e KRAVCHENKO, 2012; PETROSELLI et al., 2013, 2014; FAN et al., 2014; 
NOURANI e ZANARDO, 2014; PATEL, KATUYAR e PRASAD, 2016). Wilson e Gallant (2000) afirmam que a partir dos MDEs é possível desenvolver modelagens hidrológicas e geomorfológicas, além de extrair informações sobre solos, vegetação, insolação, dente outros, mas sempre limitado pelo refinamento da escala do MDE utilizado.

Um MDE consiste na representação matemática da distribuição do relevo da superfície terrestre, armazenado em um formato digital adequado, sendo ideal para a sua utilização computacional e permitindo a modelagem, análise e exibição de processos e fenômenos vinculados aos aspectos do relevo (BURROUGH e MCDONNELL, 1998). É importante frisar, sobretudo, que, para esse trabalho, se considera o conceito mais genérico para MDEs, no qual os mesmos podem representar a existência de objetos não topográficos (prédios, construções, árvores) sobre a superfície do terreno, ou seja, os MDEs podem não representar somente a superfície terrestre, mas também objetos localizados nessa superfície. Alguns autores também usam essa definição para se referir aos Modelos Digitais de Superfície (MDS).

Wilson (2012) aponta a superioridade dos MDEs oriundos de sensoriamento remoto em comparação com os MDEs gerados a partir de cartas topográficas tradicionais, já que o primeiro, em geral, consiste em uma superfície de levantamento mais detalhada. De acordo com Carvalho e Latrubesse (2004), os vazios de informação entre as curvas de nível nas cartas topográficas podem ocultar formas de relevo, suavizando acidentes topográficos e, por consequência, representando com menor precisão a verdade terrestre.

Atualmente, alguns MDEs oriundos de sensoriamento remoto estão disponíveis de forma gratuita e com grande abrangência global, entre esses podemos citar os produtos oriundos do SRTM, ASTER GDEM e ALOS. Para esse trabalho foi selecionado os produtos do Advanced Spaceborne Thermal Emission and Reflection Radiometer Global Elevation Model (ASTER GDEM) por ser um dos produtos de média resolução espacial (aproximadamente 30 metros) mais utilizado e testado em trabalhos 
técnicos e científicos ao longo dos últimos anos. Os dados do ASTER GDEM, lançados em 2009 e revisados em 2011, são frutos de uma ação conjunta do Ministério da Economia, Indústria e Comércio do Japão com a NASA, resultando em MDEs com cerca de 30 metros de resolução espacial (1 arcosegundo), tendo o WGS 84 como datum horizontal e vertical. Esses MDEs são oriundos de pares estereoscópicos de imagens do ASTER, sensor VNIR (faixa do infravermelho próximo), a bordo do satélite TERRA.

Diversos trabalhos afirmam que a acurácia vertical dos MDEs oriundos de sensoriamento remoto variam espacialmente e que tal variação é em função, principalmente, da configuração topográfica e cobertura vegetal do terreno, assim como dos erros aleatórios vinculados à aquisição de dados e do seu processamento (TANG et al., 2001; WECHSLER, 2007; LINDSAY e EVANS, 2008; WILSON, 2012; MUKHERJEE et al., 2013). Diante disso, há duas formas gerais de correção dos MDEs para aumentar sua acurácia vertical: a primeira forma está baseada no conhecimento detalhado da natureza e magnitude das fontes de erro, para que assim as mesmas possam ser modeladas de forma adequada a sua minimização, o que depende da disponibilidade de dados e parâmetros precisos sobre a plataforma, o sensor e a superfície da qual os dados foram adquiridos; a segunda forma é baseada na determinação de relações matemáticas entre os dados provenientes do imageamento por sensoriamento remoto e dados de referência de alta precisão para uma mesma área, essa abordagem se mostra muito mais flexível, uma vez que não é necessário o conhecimento detalhado da natureza e magnitude das fontes de erro (AUDETTE, FERRIE e PETERS, 2000; GRUEN e AKCA, 2005).

Muitos trabalhos que objetivaram a melhoria da acurácia dos MDEs provenientes de sensoriamento remoto podem ser citados: Gruen (1985); Ebner e Mueller (1986); Ebner e Strunz (1988); Rosenholm e Torlegard (1988); Johnson e Kang (1999); Maas (2000, 2001); Xu e Li (2000); Vanden, Wyngaerd e Van Gool (2003); Moura (2005); Su et al. (2014, 2015); e Fernandez, Adamowski e Petroselli (2016). No que diz respeito à segunda 
forma de correção de MDEs supracitada, destaca-se o trabalho de Elmiro, Dutra e Mura (2008), que propôs a correção de um MDE para uma parcela da Floresta Nacional de Tapajós a partir de superfícies de compensação de erro geradas por métodos determinísticos de interpolação com base em pontos de referência de alta precisão adquiridos por receptor/antena GNSS.

Elmiro, Dutra e Mura (2008) apresentaram uma metodologia eficiente e flexível para a correção de MDEs, conseguindo bons resultados com a mesma, contudo tal trabalho limitou sua avaliação a uma pequena área de $143 \mathrm{~km}^{2}$, que não possui grandes diferenças topográficas, uma vez que a variação altimétrica da mesma não ultrapassa 130 metros. Além disso, Elmiro, Dutra e Mura (2008) não avaliaram uma superfície de compensação de erro elaborada a partir da utilização de um interpolador geoestatístico.

Li, Zhu e Gold (2004) classificam os interpoladores como determinísticos, que utilizam apenas formulações matemáticas para o cálculo dos valores interpolados em funções dos pontos vizinhos, e geoestatísticos, que não fazem somente uso de formulações matemática, mas também de formulações estatísticas sobre a variabilidade espacial da variável analisada para a predição dos valores desconhecidos. Yamamoto e Landim (2013), afirmam que as estimativas por geoestatísticas são, em geral, superiores aos demais métodos de interpolação numérica, pois fazem uso de métodos estatísticos, que não consideram somente a distância entre os pontos com valores conhecidos, mas também a variabilidade espacial da variável a ser interpolada, assim como a possibilidade de ocorrência de anisotropia.

Dessa forma, esse trabalho busca avaliar a metodologia de Elmiro, Dutra e Mura (2008) para áreas mais extensas e com maior heterogeneidade topográfica, assim como a aplicação de um interpolador geoestatístico para a elaboração das superfícies de compensação de erros. Portanto, o objetivo do presente estudo é avaliar e comparar a utilização de superfícies de compensação de erro geradas por interpolações determinísticas e geoestatísticas para o aumento da acurácia vertical dos MDEs oriundos do 
ASTER GDEM para o estado do Rio de Janeiro. Para isso, foram utilizados como parâmetros de avaliação da acurácia vertical as diretrizes do Padrão de Exatidão Cartográfica dos Produtos Cartográficos Digitais (PEC-PCD), estabelecidas pela Norma da Especificação Técnica para Aquisição de Dados Geoespaciais Vetoriais de Defesa da Força Terrestre (BRASIL, 2011).

\section{1 Área de estudo}

O estado do Rio de Janeiro (Figura 1), com território de aproximadamente $44.000 \mathrm{~km}^{2}$, está localizado no extremo leste do Rift Continental do Sudeste do Brasil - RCSB (RICCOMINI, 1989; 1995), se estendendo da região de serras e de depressões interplanálticas correspondente ao vale do rio Paraíba do Sul à região dos maciços litorâneos, colinas e terrenos quaternários da Baía de Guanabara, de Jacarepaguá, de Sepetiba, da Região dos Lagos e da planície costeira de Campos. Sua geomorfologia é caracterizada por um contraste significativo das formas de relevo e uma acentuada heterogeneidade topográfica, produto da complexa evolução geológico-geomorfológica Meso-Cenozóica do sudeste brasileiro e, ainda, do processo acentuado de alteração da paisagem resultante das condições do regime climático tropical úmido (SILVA, 2002).

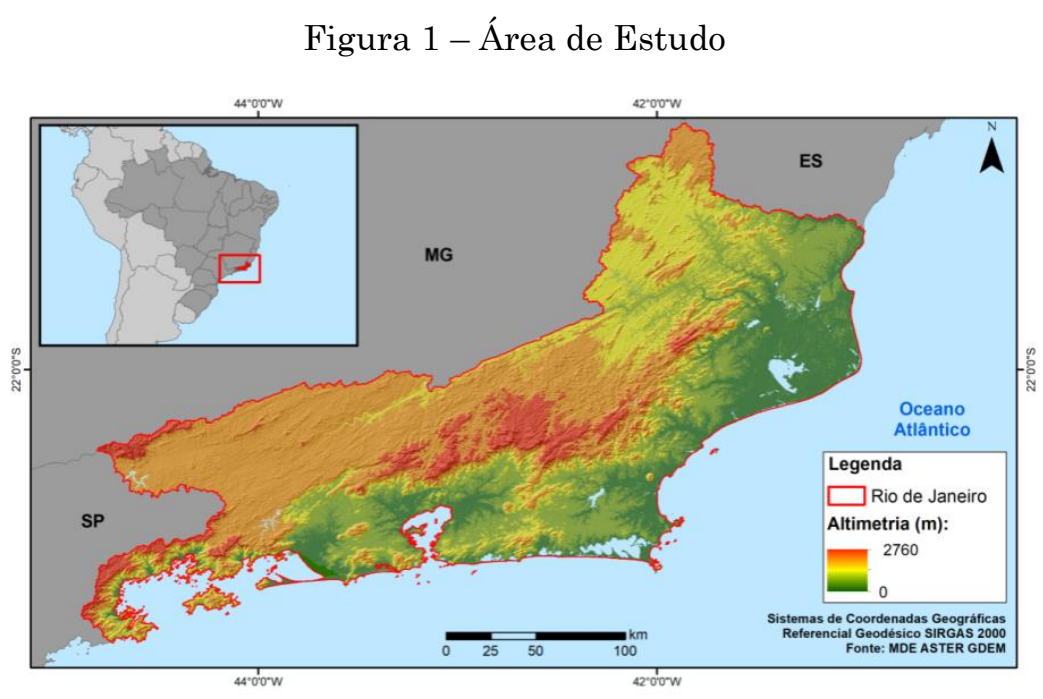

Fonte: Elaborada pelos autores. 


\title{
2 Materiais e métodos
}

\author{
2.1 Materiais
}

Para o presente estudo, foram utilizados os seguintes materiais:

a) MDE ASTER GDEM, com resolução espacial de 1 arco-segundo (aproximadamente 30 metros), no formato GeoTIF;

b) 1.419 Pontos de Controle do projeto RJ25 (IBGE) com valores de altitudes ortométricas, em formato shape (shp), datum horizontal SIRGAS 2000 e datum vertical Imbituba (MAPGEO15), levantados em campo por receptor/antena GNSS pelo método de posicionamento relativo estático, rastreados a partir de pontos da rede fundamental do IBGE, onde o erro médio do ajustamento foi menor que $30 \mathrm{~cm}$.

Optou-se por não executar a compatibilização dos datuns verticais dos MDEs e dos Pontos de Controle, uma vez que Barros (2006) destaca que não foram detectadas maiores diferenças ao se comparar MDEs com a altitude ortométrica referenciada em Imbituba com MDEs com altitudes referenciadas no WGS84 (EGM96) na área de estudo, de forma que tais diferenças são, em média, de 0,54 metros.

\subsection{Métodos}

A metodologia do presente estudo foi dividida em seis etapas (Figura 2). A primeira etapa consiste na seleção dos pontos de controle, que foram divididos em dois conjuntos: um conjunto, que foi denominado de Pontos de Controle para Correção, foi utilizado na correção dos MDEs por meio da metodologia proposta nesse trabalho, e o outro conjunto, que foi denominado 
Pontos de Controle para Avaliação, foi utilizado na avaliação com base no PEC-PCD dos MDEs corrigidos.

A segunda etapa consiste no cálculo da diferença aritmética entre as altitudes medidas para cada Ponto de Controle para Correção e as altitudes do pixel que seja seu correspondente geoespacial no MDE, de forma que tal valor seja atribuído a cada um dos Pontos de Controle para Correção.

A terceira etapa consiste na interpolação de tais diferenças por meio de dois interpoladores determinísticos, Triangulação com Interpolação Linear (TIL) e o Inverso da Distância Ponderada (Inverse Distance Weighting - IDW), e um interpolador geoestatístico, a Krigagem Ordinária, resultando assim nas denominadas superfícies de compensação de erro com resolução espacial de 1 arco-segundo (aproximadamente 30 metros), mesma resolução espacial do MDE ASTER GDEM. Também foi criada uma superfície de compensação de erro com um valor constante correspondente a média aritmética das diferenças altimétricas entre cada Ponto de Controle para Correção e as altitudes do pixel que seja seu correspondente geoespacial no MDE, esse método foi denominado nesse estudo como Deslocamento Vertical Constante (DVC).

A quarta etapa consiste na validação cruzada das interpolações e a quinta etapa corresponde ao processo de correção do MDE por meio de álgebra de mapas, no qual as superfícies de compensação de erro foram somadas ao MDE ASTER GDEM.

Por fim, os MDEs corrigidos por cada uma das superfícies geradas foram avaliados segundo o critério da PEC-PCD em relação à sua acurácia vertical para as escalas 1:50.000, 1:100.000 e 1:250.000, tendo como base os Pontos de Controle para Avaliação.

Todos os procedimentos computacionais foram executados com a utilização dos software ArcGIS (ESRI, 2016) e RStudio (RSTUDIO TEAM, 2015). 
Figura 2 - Fluxograma dos procedimentos executados

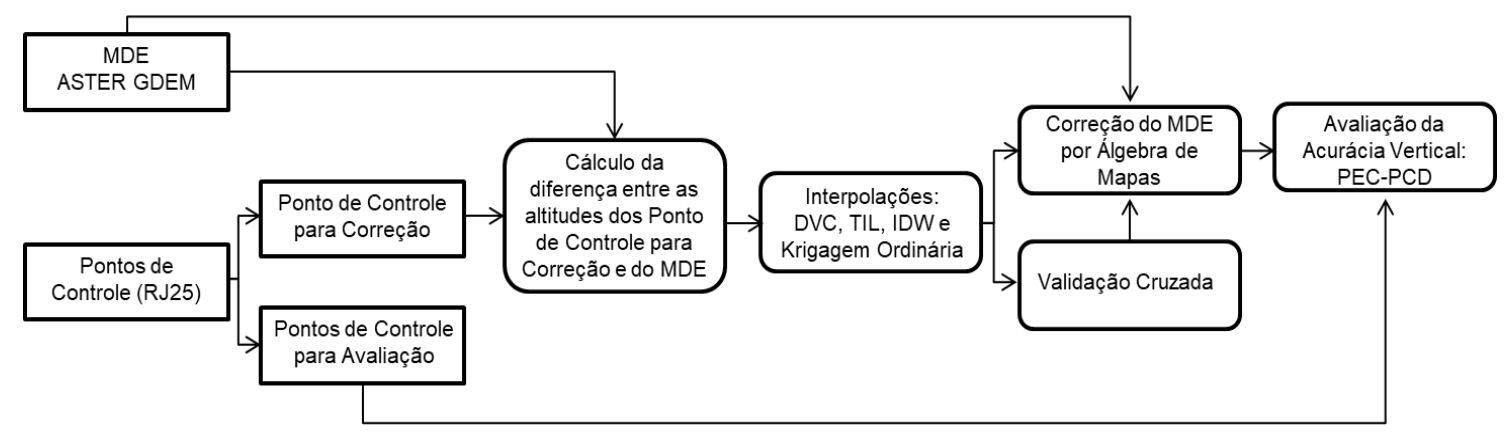

Fonte: Elaborada pelos autores.

2.2.1 Seleção dos pontos de controle para correção e dos pontos de controle para avaliação

Para a divisão dos pontos de controle em dois conjuntos: Pontos de Controle para Correção e Pontos de Controle para Avaliação, foi elaborado um grid com células de $11 \mathrm{~km} \mathrm{x} 11 \mathrm{~km}$ cobrindo toda a área de estudo. $\mathrm{O}$ tamanho das células do grid foi escolhido por meio de vários testes com tamanhos diferentes, de forma que o tamanho de $11 \mathrm{~km} \times 11 \mathrm{~km}$ foi o que obteve melhores resultados para a separação dos pontos de controle. Nas células que continham mais de um ponto de controle, foi selecionado um ponto para fazer parte do conjunto de Pontos de Controle para Avaliação. Dessa forma, os demais pontos de controle passaram a fazer parte do conjunto de Pontos de Controle para Correção. Tal metodologia garantiu uma boa representatividade espacial dos dois conjuntos de pontos de controle. Como resultado foi obtido 1015 pontos para o conjunto de Pontos de Controle para Correção e 403 pontos para o conjunto de Pontos de Controle para Avaliação (Figura 3). 
Figura 3 - Pontos de Controle para Correção e Pontos de Controle para Avaliação

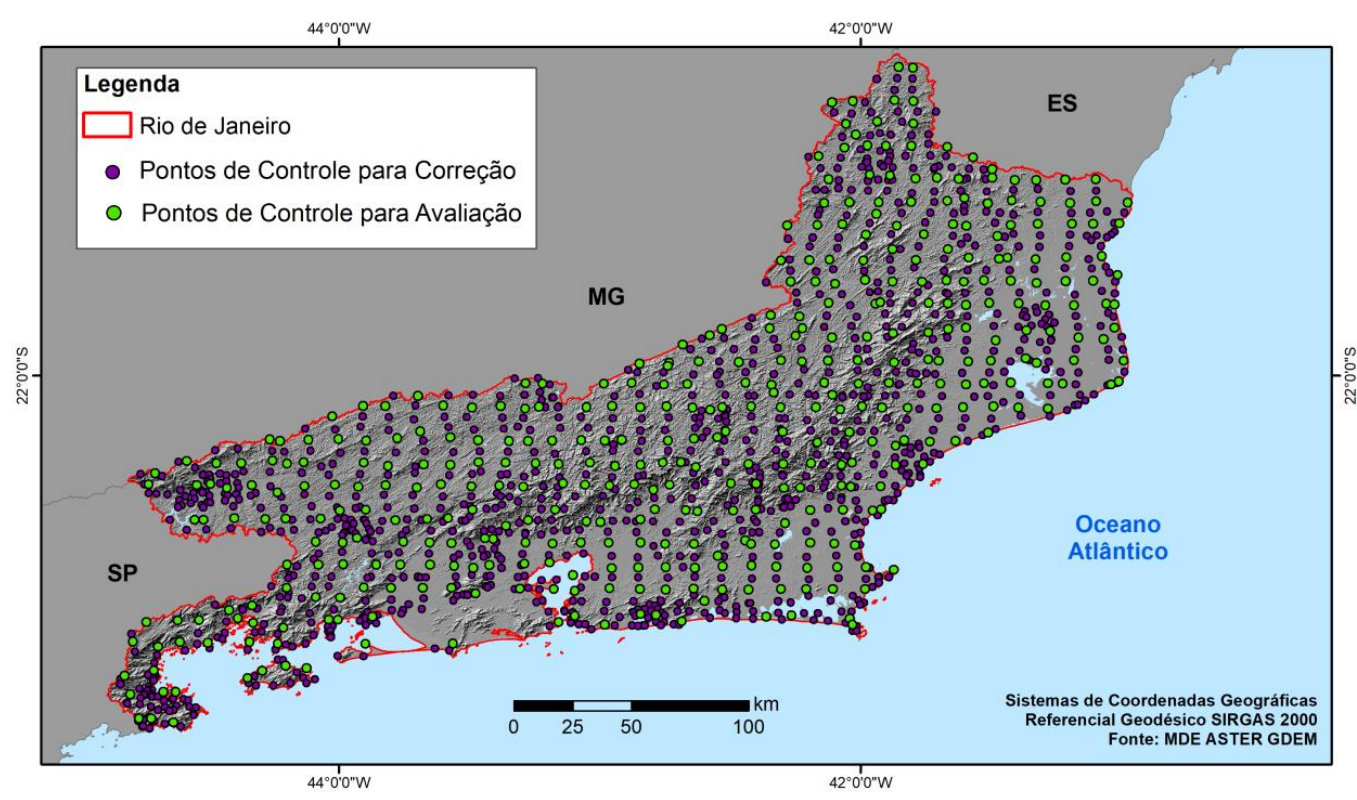

Fonte: Elaborada pelos autores.

2.2.2 Cálculo da diferença entre as altitudes dos Pontos de Controle e do MDE

Para cada ponto do conjunto de Pontos de Controle para Correção foi calculada a diferença da altitude calculada a partir dos valores registrados por receptor/antena GNSS no ponto com a altitude do pixel do MDE que correspondesse à localização geoespacial de tal ponto (Equação 1).

$$
\text { Dif }=h_{r}-h_{s}
$$

Onde, $h_{r}$ é a altitude calculada a partir dos valores registrados por receptor/antena GNSS em um ponto específico do conjunto de Pontos de Controle para Correção, $h_{s}$ é a altitude do pixel do MDE que corresponde à localização geoespacial de tal ponto e Dif é a diferença entre essas duas altitudes. Dessa forma, para cada ponto do conjunto de Pontos de Controle para Correção foi atribuído um valor referente a essa diferença. 
2.2.3 Interpolações das superfícies de compensação de erro

Antes das interpolações das superfícies de compensação de erro, foi realizada uma análise exploratória dos dados com o intuito de identificar a existência de outliers. Contudo, não foi identificado nenhum valor de diferença entre as altitudes dos Pontos de Controle para Correção e do MDE que possa ser considerado outlier.

\subsubsection{Deslocamento Vertical Constante - DVC}

O método DVC consistiu na criação de uma superfície de compensação de erro com um valor constante para toda a área de estudo referente à média das diferenças altimétricas entre cada Ponto de Controle para Correção e as altitudes do pixel que seja seu correspondente geoespacial no MDE. Tal procedimento também foi realizado por Elmiro, Dutra e Mura (2008), utilizando a equação 2 :

$$
D i f_{m}=\frac{1}{N} \sum_{i=0}^{N}\left(h_{r}-h_{s}\right)
$$

Onde, $h_{r}$ é a altitude calculada a partir dos valores registrados por receptor/antena GNSS em um ponto específico do conjunto de Pontos de Controle para Correção, $h_{s}$ é a altitude do pixel do MDE que corresponde à localização geoespacial de tal ponto, $\mathrm{N}$ é o número total de Pontos de Controle para Correção e $D i f_{m}$ é o valor utilizado para a criação da superfície de compensação de erro pelo método DVC.

O valor de $D i f_{m}$ calculado para o presente estudo foi de $-1,699$. 


\subsubsection{Triangulação com Interpolação Linear - TIL}

A TIL consiste na criação de uma malha triangular irregular baseado no algoritmo de Delaunay, que estabelece que os vértices dos triângulos devam ser os pontos amostrais, que no presente estudo são os Pontos de Controle para Correção. Os pontos amostrais são conectados de maneira que nenhuma borda do triângulo possa ser cruzada por outros triângulos. O resultado são blocos formados por faces triangulares, no qual cada triângulo define um plano no seu interior, de forma que os valores de dentro desse plano sejam estimados com base nos três pontos amostrais que formam os vértices desse triângulo. Mais detalhes sobre tal método podem ser encontrados em Burrough e Mcdonnell (1998), Shewchuk (1999), Câmara, Davis e Monteiro (2001) e Erxleben, Elder e Davis (2002).

Essa malha triangular foi então convertida para uma malha regular por interpolação linear, originando a superfície de compensação de erro pelo método TIL.

\subsubsection{Inverso da Distância Ponderada - IDW}

O IDW parte da premissa de que os locais mais próximos são mais semelhantes do que os pontos mais distantes. Dessa forma, para estimar os valores de qualquer posição não medida, a influência de cada ponto amostral é ponderada em função da distância para essa posição, ou seja, quanto mais distante o ponto da posição a ser estimada, menor é sua influência (BURROUGH e MCDONNELL, 1998; EL-SHEIMY, VALEO e HABIB, 2005).

Três parâmetros são necessários para esse interpolador: o número mínimo e máximos de amostras a serem consideradas na interpolação e a potência da função (MARCUZZO, ANDRADE e MELO, 2011). Nesse trabalho, esses parâmetros foram escolhidos a partir de vários testes, de forma, que os valores que apresentaram melhores resultados na validação 
cruzada foram os utilizados para gerar a superfície de compensação de erro pelo método IDW (Tabela 1).

Tabela 1 - Valores utilizados para cada parâmetro do interpolador IDW

\begin{tabular}{c|c|c}
\hline $\begin{array}{c}\text { Número Máximo de } \\
\text { Amostras }\end{array}$ & $\begin{array}{c}\text { Número Mínimo de } \\
\text { Amostras }\end{array}$ & $\begin{array}{c}\text { Potência da } \\
\text { Função }\end{array}$ \\
\hline 10 & 5 & 1 \\
\hline
\end{tabular}

Fonte: Elaborada pelos autores.

A equação 3 demonstra como foi calculado o valor estimado para cada localização da superfície de compensação de erro pelo método IDW:

$$
D i f_{j}=\frac{\sum_{i=1}^{n}\left(\frac{D i f_{i}}{d_{i j}{ }^{k}}\right)}{\sum_{i=1}^{n}\left(\frac{1}{d_{i j}{ }^{k}}\right)}
$$

Onde, $D i f_{j}$ é o valor interpolado para a localização $j$; Difi é o valor da diferença entre a altitude calculada a partir dos valores registrados por receptor/antena GNSS no ponto $i$ do conjunto de Pontos de Controle para Correção e a altitude do pixel do MDE que corresponde à localização geoespacial de tal ponto; $d_{i j}$ é a distância entre o ponto $i$ e a localização $j ; n$ é o número de amostras utilizadas e $k$ é a potência da função utilizada como parâmetro.

\subsubsection{Krigagem Ordinária}

Os métodos determinísticos de interpolação possuem limitações na ponderação da variabilidade espacial ao não considerarem a continuidade espacial do fenômeno e a possibilidade de anisotropia do mesmo (CAMARGO, 1998; VIEIRA, 2000). A krigagem surge na tentativa se superar tais limitações, de forma que sua aplicabilidade pressupõe uma análise espacial prévia do fenômeno a ser interpolado (VIEIRA, 2000). 
Dos diversos tipos de krigagem, Yamamoto e Landim (2013) destacam como as mais utilizadas: a krigagem simples, que assume que a média seja estatisticamente constante para toda a área; e a krigagem ordinária, que considera que a média seja flutuante por toda a área. No caso do presente estudo, foi utilizada a krigagem ordinária.

A primeira etapa para a utilização adequada da krigagem é a análise exploratória dos dados com o intuito de identificar a existência de outliers e/ou tendências (GUIMARÃES, 2004; VILELA, 2004). No presente estudo, os dados já foram analisados e foi descartada a existência de outliers, de forma que primeira etapa para a krigagem consistiu na construção e interpretação de gráficos de tendência.

A segunda etapa consiste na construção do semivariograma experimental, que é considerado a ferramenta básica para a krigagem, uma vez que possibilita representar quantitativamente a variação de um fenômeno regionalizado no espaço (CAMARGO, FUCKS e CÂMARA, 2004). O semivariograma expressa a dependência espacial através da medida da variância dos valores amostrais, separados por uma distância (WANDERLEY, AMORIM e CARVALHO, 2012). O semivariograma pode ser calculado para várias direções, no intuito de verificar a ocorrência ou não de anisotropia do fenômeno. Para o cálculo do semivariograma, é utilizada a equação (4):

$$
y(h)=\frac{1}{2 N(h)} \sum_{i=1}^{N}\left[Z\left(x_{i}\right)-Z\left(x_{i}+h\right)\right]^{2}
$$

Onde, $y(h)$ é a semivariância amostral que depende de $h$; $h$ é distância entre duas amostras; $N(h)$ é o número de amostrais que estão distanciadas no máximo pela distância $h ; Z\left(x_{i}\right)$ valor medido na amostra $x_{i}$; e $Z\left(x_{i}+h\right)$ valor medido na amostra distanciada $h$ de $x_{i}$.

De acordo com Vieira (2000), se espera que a variância aumente com a distância $h$ até um valor máximo, onde ela se estabilizará. O ponto de 
estabilização do semivariograma é denominado de patamar e a partir desse ponto não há mais dependência espacial entre as amostras. A distância onde se atinge o patamar é chamada de alcance, que consiste na distância em que as amostras ainda são dependentes espacialmente. Há também uma variância aleatória próxima ao ponto amostral que é denominado de efeito pepita.

A terceira etapa para a krigagem ordinária diz respeito ao ajuste do semivariograma experimental por meio de modelos teóricos. Um bom ajuste nessa etapa é fundamental para bons resultados provenientes da krigagem, uma vez que o modelo do semivariograma ajustado é o que vai definir os pesos a serem associados a cada uma das amostras para a interpolação em cada ponto não medido na área de estudo (VILELA, 2004; SANTOS, 2010; WANDERLEY, AMORIM e CARVALHO, 2012; YAMAMOTO e LANDIM, 2013).

A última etapa consiste na interpolação por krigagem ordinária, que foi então realizada através da equação (5):

$$
D i f_{j}=\sum_{i=1}^{n} \omega_{i} D i f_{i}
$$

Onde, $D i f_{j}$ é o valor interpolado para a localização $j$; $D i f_{i}$ é o valor da diferença entre a altitude calculada a partir dos valores registrados por receptor/antena GNSS no ponto $i$ do conjunto de Pontos de Controle para Correção e a altitude do pixel do MDE que corresponde à localização geoespacial de tal ponto; e $\omega_{i}$ o peso atribuído ao ponto i para a interpolação da localização $j$.

\subsubsection{Validação cruzada}

Qualquer que seja o método de estimação/interpolação, sempre existirá níveis de incertezas inerentes ao processo, que podem estar 
relacionadas às hipóteses assumidas ou mesmo aos parâmetros utilizados na modelagem (SANTOS, 2010).

A validação cruzada é um método para quantificar tal incerteza, de forma que a mesma consiste na estimativa de cada ponto amostral, como se o mesmo não existisse no conjunto amostral utilizado no processo de estimação/interpolação. No final deste procedimento, se têm para cada ponto amostral seu valor real e seu valor estimado, caso o mesmo não fizesse parte do conjunto amostral. A partir desses dados, é possível realizar inúmeras análises estatísticas para avaliar o método de estimação/interpolação utilizado (VIEIRA, 2000; SANTOS, 2010; SANTANA e SANTOS, 2016).

Nesse estudo, todos os métodos de interpolação das superfícies de compensação de erro foram avaliados pela validação cruzada, com exceção do método DVC. Sendo assim, duas formas de avaliar os resultados da validação cruzada foram utilizadas: a primeira forma consiste na construção de gráfico de dispersão dos valores estimados versus os valores reais dos pontos amostrais, de forma que quanto mais próximo de $45^{\circ}$ estiver a linha de tendência do gráfico em relação ao eixo $\mathrm{x}$, melhores foram os resultados obtidos na validação cruzada; a segunda forma foi por meio do cálculo do erro médio quadrático (EMQ) (Equação 6), de forma que quanto menor o EMQ, melhores foram os resultados obtidos na validação cruzada

$$
E M Q=\sqrt{\frac{\sum\left(V_{e}-V_{r}\right)^{2}}{n-1}}
$$

Onde, $V_{e}$ é o valor estimado para cada ponto amostral; $V_{r}$ é o valor real para cada ponto amostral e $n$ é o número total de pontos amostrais.

\subsubsection{Correção do MDE por álgebra de mapas}

Uma vez obtidas as superfícies de compensação de erro por cada método de interpolação utilizado (DVC, TIL, IDW e Krigagem Ordinária), 
cada uma das mesmas foram somadas, por álgebra de mapas, ao MDE ASTER GDEM original, resultando nos MDEs corrigidos.

\subsubsection{Avaliação da acurácia vertical dos MDEs corrigidos}

Cada MDE corrigido foi avaliado com base no PEC-PCD (BRASIL, 2011) para as escalas 1:50.000, 1:100.000 e 1:250.000. O PEC-PCD utiliza como parâmetros de avaliação: a tolerância vertical (TV), que consiste em 90\% dos valores das variações entre a altitude dos pixels do MDE corrigido e altitudes medidas nos Pontos de Controle para Avaliação correspondentes espacialmente a tais pixels estarem dentro de um limite definido; e o EMQ, calculado pela equação (7):

$$
E M Q=\sqrt{\frac{\sum\left(Z_{m d e}-Z_{P C A}\right)^{2}}{n-1}}
$$

Onde, $Z_{m d e}$ é altitude de cada pixel do MDE corrigido; $Z_{P C A}$ é a altitude medida nos Ponto de Controle para Avaliação correspondente espacialmente a tal pixel e $n$ é o número total de Ponto de Controle para Avaliação.

Segundo o PEC-PCD, os MDEs podem ser classificados em quatro classes: A, B, C e D. Para a classe A, 90\% das variações entre as altitudes do MDE e as altitudes de pontos de controle devem ser de até 0,27 vezes a equidistância entre as curvas-de-nível e o EMQ deve ser de até um sexto desta equidistância. Para a classe B, 90\% das variações entre as altitudes do MDE e as altitudes de pontos de controle devem ser de até metade da equidistância entre as curvas-de-nível e o EMQ deve ser de até um terço desta equidistância. Para a classe C, 90\% das variações entre as altitudes do MDE e as altitudes de pontos de controle devem ser de até três quintos da equidistância entre as curvas-de-nível e o EMQ deve ser de até dois quintos desta equidistância. Para a classe D, 90\% das variações entre as altitudes do 
MDE e as altitudes de pontos de controle devem ser de até três quartos da equidistância entre as curvas-de-nível e o EMQ deve ser de até a metade desta equidistância (Tabela 2).

Tabela 2 - Limiares de TV e do EMQ para cada classe do PEC-PCD para as escalas $1: 50.000,1: 100.000$ e $1: 250.000$

\begin{tabular}{c|c|c|c|c|c}
\hline Escala & Classe & A & B & C & D \\
\hline \multirow{2}{*}{$\mathbf{1 : 5 0 . 0 0 0}$} & TV & $5,5 \mathrm{~m}$ & $10 \mathrm{~m}$ & $12 \mathrm{~m}$ & $15 \mathrm{~m}$ \\
\cline { 2 - 6 } & EMQ & $3,33 \mathrm{~m}$ & $6,7 \mathrm{~m}$ & $8 \mathrm{~m}$ & $10 \mathrm{~m}$ \\
\hline \multirow{2}{*}{$\mathbf{1 : 1 0 0 . 0 0 0}$} & TV & $13,7 \mathrm{~m}$ & $25 \mathrm{~m}$ & $30 \mathrm{~m}$ & $37,5 \mathrm{~m}$ \\
\cline { 2 - 6 } & EMQ & $8,33 \mathrm{~m}$ & $16,7 \mathrm{~m}$ & $20 \mathrm{~m}$ & $25 \mathrm{~m}$ \\
\hline \multirow{2}{*}{$\mathbf{1 : 2 5 0 . 0 0 0}$} & TV & $27 \mathrm{~m}$ & $50 \mathrm{~m}$ & $60 \mathrm{~m}$ & $75 \mathrm{~m}$ \\
\cline { 2 - 6 } & EMQ & $16,67 \mathrm{~m}$ & $33,3 \mathrm{~m}$ & $40 \mathrm{~m}$ & $50 \mathrm{~m}$ \\
\hline
\end{tabular}

Fonte: PEC-PCD (BRASIL, 2011).

Para compreender melhor as características de acurácia vertical de cada MDE corrigido, também foram calculadas estatísticas descritivas das diferenças relativas e absolutas entre a altitude dos pixels do MDE corrigido e altitudes medidas nos Pontos de Controle para Avaliação correspondentes espacialmente a tais pixels: valor mínimo e valor máximo, primeiro e terceiro quartis; mediana; média; e desvio padrão.

\section{Resultados}

\subsection{Avaliação da acurácia vertical do MDE ASTER GDEM}

Para fins de comparação dos resultados obtidos para a correção do MDE ASTER GDEM original a partir das diferentes superfícies de compensação de erro elaboradas, o MDE ASTER GDEM original foi avaliado quanto a sua acurácia vertical para as escalas 1:50.000, 1:100.000 e 1:250.000 com base na PEC-PCD. Para isso, foram utilizados os Pontos de Controle para Avaliação, ou seja, o mesmo conjunto de pontos utilizados para avaliar a acurácia vertical dos MDEs corrigidos. 
O EMQ obtido para o MDE ASTER GDEM original foi de 7,66 e os resultados para a TV podem ser observados na Tabela 3. Dessa forma, o MDE ASTER GDEM original analisado obteve, segundos os critérios da PEC-PCD, classe D para a escala 1:50.000 e classe A para as escalas $1: 100.000$ e $1: 250.000$.

Tabela 3 - Valores de TV do MDE ASTER GDEM original para as escalas 1:50.000, $1: 100.000$ e $1: 250.000$

\begin{tabular}{c|c|c|c}
\hline $\begin{array}{c}\text { Classe PEC- } \\
\text { PCD }\end{array}$ & $\mathbf{1 : 5 0 . 0 0 0 ( \% )}$ & $\mathbf{1 : 1 0 0 . 0 0 0 ( \% )}$ & $\mathbf{1 : 2 5 0 . 0 0 0 ~ ( \% )}$ \\
\hline A & 56,18 & 92,30 & 99,72 \\
\hline B & 84,13 & 99,74 & 100,00 \\
\hline C & 89,48 & 99,98 & 100,00 \\
\hline D & 94,79 & 100,00 & 100,00 \\
\hline- & 5,21 & 0,00 & 0,00 \\
\hline
\end{tabular}

Fonte: Elaborada pelos autores.

A Tabela 4 apresenta as estatísticas descritivas das diferenças relativas e absolutas entre os valores altimétricos do MDE ASTER GDEM e os valores altimétricos dos Pontos de Controle para Avaliação correspondentes. Tais resultados consistem em mais um parâmetro de comparação dos resultados obtidos por cada um dos métodos de correção do MDE ASTER GDEM original a partir das diferentes superfícies de compensação de erro elaboradas.

Tabela 4 - Estatística descritiva das diferenças relativas e absolutas entre os valores altimétricos do MDE ASTER GDEM e os Pontos de Controle para Avaliação correspondentes

\begin{tabular}{c|c|c}
\hline ASTER GDEM (Original) & Diferença Relativa & Diferença Absoluta \\
\hline Média & 1,31 & 5,82 \\
\hline Valor Mínimo & $-23,18$ & 0,01 \\
\hline Valor Máximo & 31,84 & 31,84 \\
\hline $\mathbf{1}^{\circ}$ Quartil & $-3,09$ & 2,25 \\
\hline Mediana & 1,53 & 4,58 \\
\hline $\mathbf{3}^{\circ}$ Quartil & 5,94 & 8,18 \\
\hline Desvio Padrão & 7,35 & 4,76 \\
\hline
\end{tabular}

Fonte: Elaborada pelos autores. 


\subsection{Deslocamento Vertical Constante - DVC}

O DVC é um método simples de correção de MDE, tendo um menor custo computacional e sendo o método que exige menor esforço geral para a sua elaboração. Contudo, é um método limitado, pois só permite correções uniformes nos MDEs, uma vez que não leva em consideração a variação espacial desigual dos erros por toda a área de estudo.

Por se tratar de um método de correção de MDE com base em valores constantes, a validação cruzada não se aplica como forma de avaliação da correção do MDE pelo método DVC. Dessa forma, para o método DVC, só foi realizada a avaliação da acurácia vertical do MDE corrigido com base na PEC-PCD como forma de avaliação da eficiência de tal método na correção do MDE ASTER GDEM para a área de estudo.

O EMQ obtido para o MDE ASTER GDEM corrigido pelo método DVC foi de 7,29 e os resultados para a TV podem ser observados na Tabela 5. Dessa forma, o MDE ASTER GDEM corrigido pelo método DVC obteve, segundos os critérios da PEC-PCD, classe D para a escala 1:50.000 e classe A para as escalas 1:100.000 e 1:250.000.

Tabela 5 - Valores de TV do MDE ASTER GDEM corrigido pelo método DVC para as escalas 1:50.000, 1:100.000 e 1:250.000

\begin{tabular}{c|c|c|c}
\hline $\begin{array}{c}\text { Classe PEC- } \\
\text { PCD }\end{array}$ & $\mathbf{1 : 5 0 . 0 0 0 ~ ( \% )}$ & $\mathbf{1 : 1 0 0 . 0 0 0 ~ ( \% )}$ & $\mathbf{1 : 2 5 0 . 0 0 0 ~ ( \% )}$ \\
\hline A & 61,78 & 92,55 & 100,00 \\
\hline B & 85,60 & 99,75 & 100,00 \\
\hline C & 88,58 & 100,00 & 100,00 \\
\hline D & 93,79 & 100,00 & 100,00 \\
\hline- & 6,21 & 0,00 & 0,00 \\
\hline
\end{tabular}

Fonte: Elaborada pelos autores.

A Tabela 6 apresenta as estatísticas descritivas das diferenças relativas e absolutas entre os valores altimétricos do MDE ASTER GDEM corrigido pelo método DVC e os valores altimétricos dos Pontos de Controle para Avaliação correspondentes. 
Tabela 6 - Estatística descritiva das diferenças relativas e absolutas entre os valores altimétricos do MDE ASTER GDEM corrigido pelo método DVC e os Pontos de Controle para Avaliação correspondentes

\begin{tabular}{c|c|c}
\hline ASTER GDEM (DVC) & Diferença Relativa & Diferença Absoluta \\
\hline Média & $-0,45$ & 5,49 \\
\hline Valor Mínimo & $-24,88$ & 0,01 \\
\hline Valor Máximo & 33,14 & 33,14 \\
\hline $\mathbf{1}^{\circ}$ Quartil & $-4,56$ & 1,92 \\
\hline Mediana & $-0,24$ & 4,37 \\
\hline $\mathbf{3}^{\circ}$ Quartil & 4,00 & 7,53 \\
\hline Desvio Padrão & 7,30 & 4,79 \\
\hline
\end{tabular}

Fonte: Elaborada pelos autores.

Ainda que o método DVC de correção do MDE consista em um método trivial e utilize premissas simplórias, o mesmo alcançou algumas melhoras na acurácia vertical do MDE ASTER GDEM para a área de estudo. No que se refere ao EMQ, teve uma melhora de 0,37, reduzindo de 7,66 para 7,29, o que corresponde a uma diminuição de cerca de 5\%. Em relação à TV, destaca-se que os percentuais de pontos na classe A aumentaram em todas as escalas analisadas (1:50.000, 1:100.000 e 1:250.000).

As estatísticas descritivas das diferenças relativas e absolutas entre os valores altimétricos do MDE ASTER GDEM corrigido pelo método DVC e os Pontos de Controle para Avaliação correspondentes também registraram uma pequena melhora do MDE corrigido para o MDE original. O valor médio das diferenças absolutas diminui de 5,82 para 5,49 e o desvio padrão das diferenças relativas diminuiu de 7,35 para 7,30. Contudo, o valor de desvio padrão para as diferenças absolutas aumentou de 4,76 para 4,79 .

\subsection{Triangulação com Interpolação Linear - TIL}

A superfície de compensação de erro pelo método TIL é apresentada na Figura 4. Vale reforçar que tal superfície de compensação de erro é limitada pela extensão espacial dos pontos amostrais, de forma que a mesma não preenche toda a borda nordeste da área de estudo. 
Figura 4 - Superfície de compensação de erro pelo método TIL

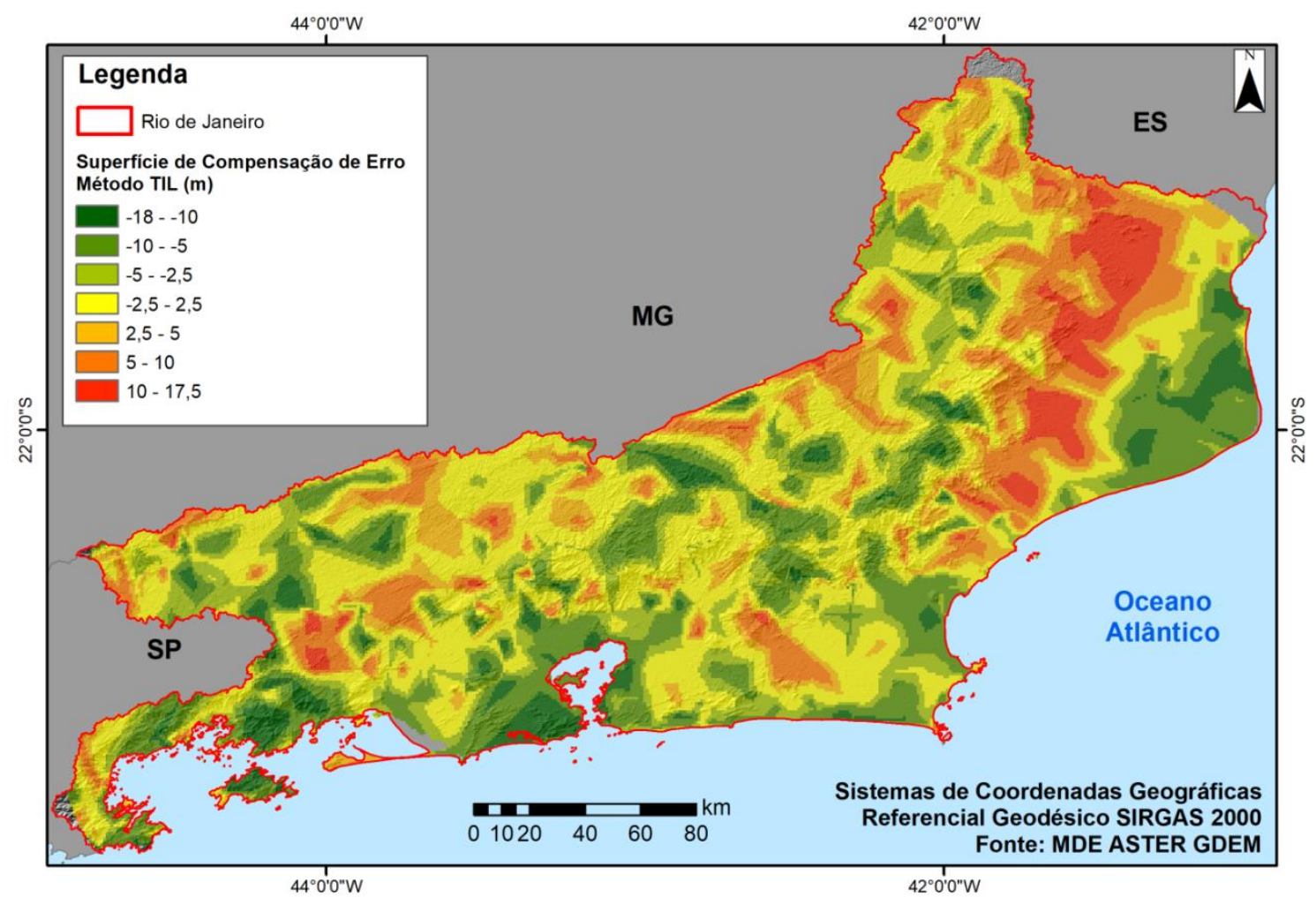

Fonte: Elaborada pelos autores.

A superfície de compensação de erro gerada pelo método TIL possui valores variando de $-17,61$ a 17,18 , uma média de $-0,87$ e um desvio padrão de 5,87. A avaliação por validação cruzada obteve um EMQ de 6,16 e o gráfico de dispersão gerado pode ser observado na Figura 5. 
Figura 5 - Gráfico de dispersão da validação cruzada para a superfície de compensação de erro pelo método TIL

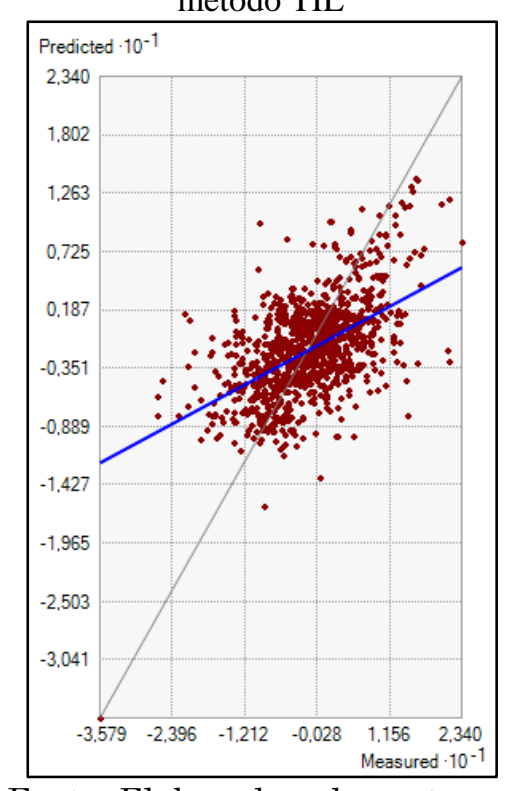

Fonte: Elaborada pelos autores.

A avaliação da acurácia vertical do MDE corrigido pelo método TIL com base na PEC-PCD obteve um EMQ de 6,48 e os resultados para a TV podem ser observados na Tabela 7. Dessa forma, o MDE ASTER GDEM corrigido pelo método TIL obteve, segundos os critérios da PEC-PCD, classe C para a escala 1:50.000 e classe A para as escalas 1:100.000 e 1:250.000.

Tabela 7 - Valores de TV do MDE ASTER GDEM corrigido pelo método TIL para as escalas $1: 50.000,1: 100.000$ e $1: 250.000$

\begin{tabular}{c|c|c|c}
\hline $\begin{array}{c}\text { Classe PEC- } \\
\text { PCD }\end{array}$ & $\mathbf{1 : 5 0 . 0 0 0 ~ ( \% )}$ & $\mathbf{1 : 1 0 0 . 0 0 0 ~ ( \% )}$ & $\mathbf{1 : 2 5 0 . 0 0 0 ~ ( \% )}$ \\
\hline A & 66,75 & 95,72 & 100,00 \\
\hline B & 87,40 & 100,00 & 100,00 \\
\hline C & 91,93 & 100,00 & 100,00 \\
\hline D & 97,97 & 100,00 & 100,00 \\
\hline- & 2,03 & 0,00 & 0,00 \\
\hline
\end{tabular}

Fonte: Elaborada pelos autores.

A Tabela 8 apresenta as estatísticas descritivas das diferenças relativas e absolutas entre os valores altimétricos do MDE ASTER GDEM corrigido pelo método TIL e os valores altimétricos dos Pontos de Controle para Avaliação correspondentes. 
Tabela 8 - Estatística descritiva das diferenças relativas e absolutas entre os valores altimétricos do MDE ASTER GDEM corrigido pelo método TIL e os Pontos de Controle para Avaliação correspondentes

\begin{tabular}{c|c|c}
\hline ASTER GDEM (TIL) & Diferença Relativa & Diferença Absoluta \\
\hline Média & 0,25 & 4,97 \\
\hline Valor Mínimo & $-22,54$ & 0,03 \\
\hline Valor Máximo & 21,24 & 22,54 \\
\hline $\mathbf{1}^{\circ}$ Quartil & $-3,48$ & 1,92 \\
\hline Mediana & $-0,04$ & 3,73 \\
\hline $\mathbf{3}^{\circ}$ Quartil & 4,37 & 7,24 \\
\hline Desvio Padrão & 6,47 & 4,15 \\
\hline \multicolumn{2}{|c|}{}
\end{tabular}

Fonte: Elaborada pelos autores.

O método TIL alcançou significativas melhoras na acurácia vertical do MDE ASTER GDEM para a área de estudo. No que se refere ao EMQ, teve uma melhora de 1,18 , reduzindo de 7,66 para 6,48 , o que corresponde a uma diminuição de cerca de $15,4 \%$. Em relação à TV, destaca-se que os percentuais de pontos na classe A aumentaram em todas as escalas analisadas (1:50.000, 1:100.000 e 1:250.000), assim como os percentuais acumulados das classes B e C aumentaram nas escalas 1:50.000 e 1:100.000, o que fez o MDE corrigido pelo método TIL alcançar a classe C da PEC-PCD para a escala 1.50.000.

As estatísticas descritivas das diferenças relativas e absolutas entre os valores altimétricos do MDE ASTER GDEM corrigido pelo método TIL e os Pontos de Controle para Avaliação correspondentes também registraram uma melhora significante do MDE corrigido para o MDE original. O valor médio das diferenças absolutas diminui de 5,82 para 4,97, os valores máximos também diminuíram de 31,84 para 22,54 e o desvio padrão das diferenças relativas e absolutas diminuíram, respectivamente, de 7,35 para 6,47 e de 4,76 para 4,15 .

\subsection{Inverso da Distância Ponderada - IDW}

O IDW é um interpolador que generaliza a ideia de média móvel local, de forma que a densidade do fenômeno tenda a variar localmente de 
maneira suave, sem descontinuidades abruptas. Contudo, essa suavização depende diretamente dos pontos amostrais utilizados para a interpolação, pois se existirem duas amostras próximas com valores discrepantes, a superfície torna-se pouco suavizada. Dessa forma, a superfície de compensação de erro gerada pelo método IDW (Figura 6) possui uma maior suavização, com descontinuidades menos abruptas do que a superfície de compensação de erro gerada pelo método TIL (Figura 4).

Figura 6 - Superfície de compensação de erro pelo método IDW

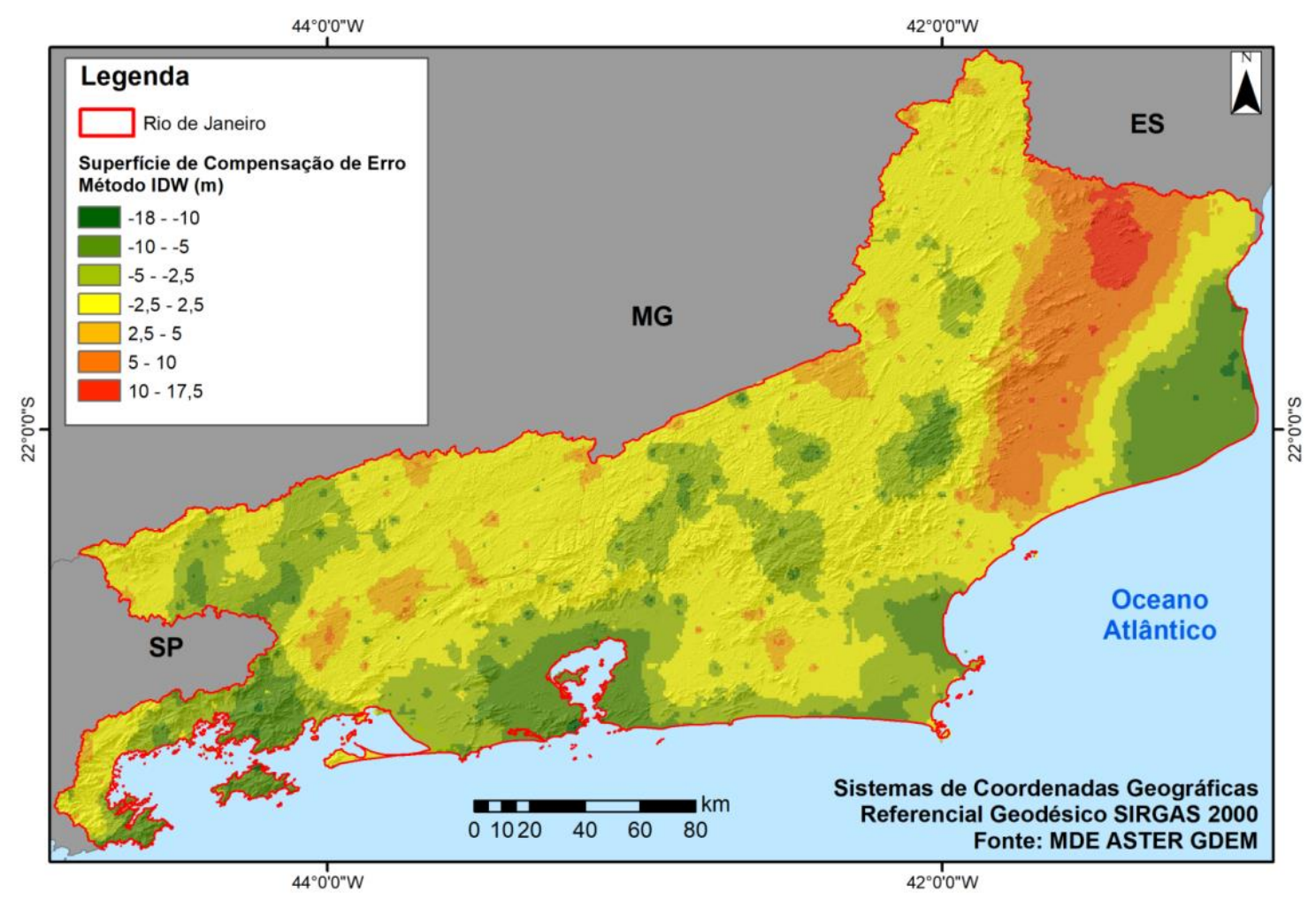

Fonte: Elaborada pelos autores.

A superfície de compensação de erro gerada pelo método IDW possui valores variando de $-15,95$ a 14,14, média de $-0,89$ e um desvio padrão de 4,07. A avaliação por validação cruzada obteve um EMQ de 5,76 e o gráfico de dispersão gerado pode ser observado na Figura 7. 
Figura 7 - Gráfico de dispersão da validação cruzada para a superfície de compensação de erro pelo método IDW

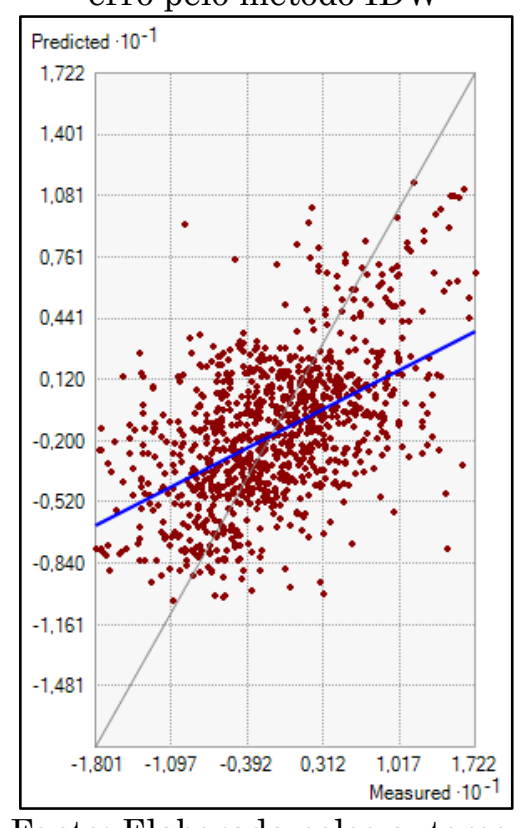

Fonte: Elaborada pelos autores.

A avaliação da acurácia vertical do MDE corrigido pelo método IDW com base na PEC-PCD obteve um EMQ de 6,04 e os resultados para a TV podem ser observados na Tabela 9. Dessa forma, o MDE ASTER GDEM corrigido pelo método IDW obteve, segundos os critérios da PEC-PCD, classe C para a escala 1:50.000 e classe A para as escalas 1:100.000 e 1:250.000.

Tabela 9 - Valores de TV do MDE ASTER GDEM corrigido pelo método IDW para as escalas 1:50.000, 1:100.000 e 1:250.000

\begin{tabular}{c|c|c|c}
\hline $\begin{array}{c}\text { Classe PEC- } \\
\text { PCD }\end{array}$ & $\mathbf{1 : 5 0 . 0 0 0 ~ ( \% )}$ & $\mathbf{1 : 1 0 0 . 0 0 0 ~ ( \% )}$ & $\mathbf{1 : 2 5 0 . 0 0 0 ~ ( \% ) ~}$ \\
\hline A & 69.00 & 96,25 & 100,00 \\
\hline B & 89,5 & 100,00 & 100,00 \\
\hline C & 94,75 & 100,00 & 100,00 \\
\hline D & 97,25 & 100,00 & 100,00 \\
\hline- & 2,75 & 0,00 & 0,00 \\
\hline
\end{tabular}

Fonte: Elaborada pelos autores.

A Tabela 10 apresenta as estatísticas descritivas das diferenças relativas e absolutas entre os valores altimétricos do MDE ASTER GDEM corrigido pelo método IDW e os valores altimétricos dos Pontos de Controle para Avaliação correspondentes. 
Tabela 10 - Estatística descritiva das diferenças relativas e absolutas entre os valores altimétricos do MDE ASTER GDEM corrigido pelo método IDW e os Pontos de Controle para Avaliação correspondentes

\begin{tabular}{c|c|c}
\hline ASTER GDEM (IDW) & Diferença Relativa & Diferença Absoluta \\
\hline Média & 0,37 & 4,56 \\
\hline Valor Mínimo & $-20-27$ & 0,02 \\
\hline Valor Máximo & 18,05 & 20,27 \\
\hline $\mathbf{1}^{\circ}$ Quartil & $-2,79$ & 1,73 \\
\hline Mediana & $-0,35$ & 3,31 \\
\hline $\mathbf{3}^{\circ}$ Quartil & 3,78 & 6,48 \\
\hline Desvio Padrão & 6,02 & 3,95 \\
\hline
\end{tabular}

Fonte: Elaborada pelos autores.

Assim como o método TIL, o método IDW alcançou significativas melhoras na acurácia vertical do MDE ASTER GDEM para a área de estudo. No que se refere ao EMQ, teve uma melhora de 1,62, reduzindo de 7,66 para 6,04, o que corresponde a uma diminuição de cerca de 21,15\%. Em relação à TV, destaca-se que os percentuais de pontos na classe $\mathrm{A}$ aumentaram em todas as escalas analisadas (1:50.000, 1:100.000 e 1:250.000), assim como os percentuais acumulados das classes B e C aumentaram nas escalas 1:50.000 e 1:100.000, o que fez o MDE corrigido pelo método IDW alcançar a classe C da PEC-PCD para a escala 1:50.000.

As estatísticas descritivas das diferenças relativas e absolutas entre os valores altimétricos do MDE ASTER GDEM corrigido pelo método IDW e os Pontos de Controle para Avaliação correspondentes também registraram uma melhora significante do MDE corrigido para o MDE original. O valor médio das diferenças absolutas diminui de 5,82 para 4,56, os valores máximos também diminuíram de 31,84 para 20,27 e o desvio padrão das diferenças relativas e absolutas diminuíram, respectivamente, de 7,35 para 6,02 e de 4,76 para 3,95 .

\subsection{Krigagem Ordinária}

Por se tratar de um método mais robusto de interpolação, a krigagem necessita de algumas etapas para a sua execução ótima. Uma dessas etapas consiste na análise espacial prévia do fenômeno a ser interpolado. A 
primeira etapa da análise espacial prévia consistiu na análise exploratória dos dados visando identificar outliers, de forma que não foram encontrados outliers no conjunto amostral utilizado para a criação das superfícies de compensação de erro. Porém, outra etapa importante da análise espacial prévia é a identificação de tendências nos dados do conjunto amostral por meio da construção e interpretação do gráfico de tendência (Figura 8).

Figura 8 - Gráfico de tendência dos dados do conjunto amostral utilizado para a criação das superfícies de compensação de erro

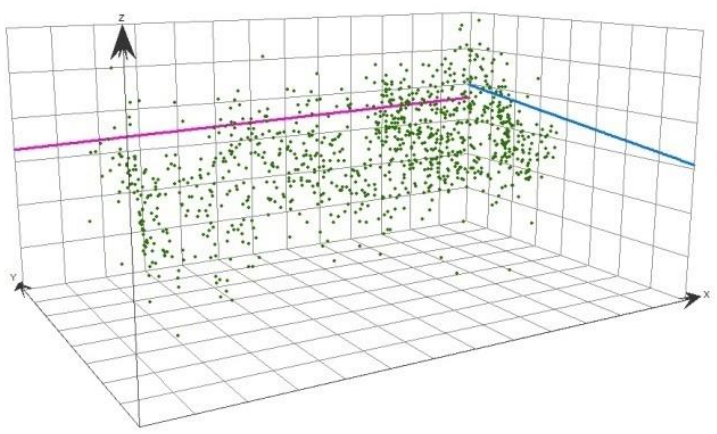

Fonte: Elaborada pelos autores.

Analisando a Figura 8, fica evidente a presença de uma tendência de primeira ordem nos dados do conjunto amostral utilizado para a criação das superfícies de compensação de erro. Uma vez que tal tendência é constatada, a mesmo é eliminada para o processo de krigagem ordinária, ou seja, é feito um ajuste de polinômios para remover a tendência e a krigagem ordinária é realizada com base nos resíduos.

Uma vez já realizada a análise exploratória dos dados em busca de outliers e a análise de tendência, a etapa seguinte consiste na construção do semivariograma experimental. Dessa forma, com o objetivo de verificar a existência ou não de anisotropia nos dados, foi construído semivariogramas nas direções: N-S $\left(0^{\circ}\right)$, SW-NE $\left(45^{\circ}\right)$, E-W $\left(90^{\circ}\right)$ e NW-SE $\left(135^{\circ}\right)$. Tais semivariogramas demonstraram que as diferenças entre as altitudes dos Pontos de Controle para Correção e do MDE possuem padrões de dependência espacial muito semelhantes em todas as direções, se tratando assim de um fenômeno isotrópico. Portanto, foi utilizado somente um 
semivariograma para a krigagem, o denominado semivariograma omnidirecional.

O semivariograma foi modelado de forma que apresentasse o melhor ajuste à realidade e o melhor resultado da validação cruzada. $\mathrm{O}$ modelo teórico que melhor se adequou ao modelo experimental foi o stable, que consiste em uma combinação do modelo exponencial e do modelo gaussiano. O modelo stable possui um parâmetro, que varia de 0 a 2 , de forma que quanto mais próximo de 0 , o modelo resultante mais se aproxima do modelo exponencial, e quanto mais próximo de 2, o modelo resultante mais se assemelha ao modelo gaussiano. Dessa forma, os valores aplicados para a configuração do semivariogama omnidirecional experimental e do modelo ajustado utilizados nesse estudo (Figura 9) são apresentados na Tabela 11.

Figura 9 - Semivariograma omnidirecional experimental e modelo ajustado

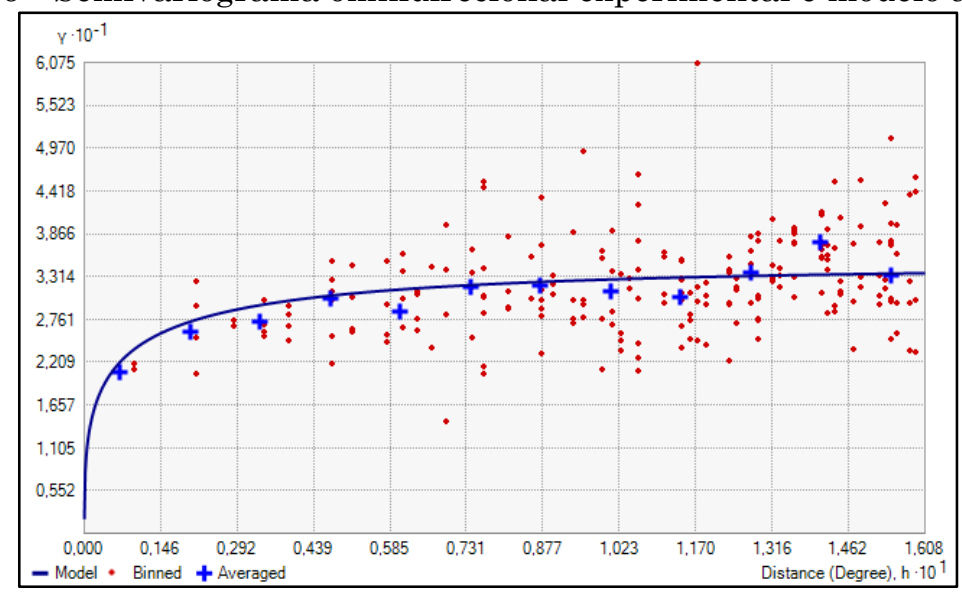

Fonte: Elaborada pelos autores.

Tabela 11 - Valores aplicados para a modelagem do semivariogama omnidirecional experimental utilizado nesse estudo

\begin{tabular}{c|c}
\hline Parâmetros & Valor \\
\hline Efeito Pepita & $1,8541 \mathrm{~m}^{2}$ \\
\hline Patamar & $32,6687 \mathrm{~m}^{2}$ \\
\hline Alcance & $0,1072^{\mathbf{0}}$ \\
\hline Parâmetro (Stable) & 0,4110 \\
\hline
\end{tabular}

Fonte: Elaborada pelos autores.

A Figura 10 apresenta a superfície de compensação de erro gerada pelo método de Krigagem Ordinária, que, assim como a superfície de compensação de erro gerada pelo método IDW (Figura 6), possui uma maior 
suavização do que a superfície de compensação de erro gerada pelo método TIL (Figura 4), ainda que em menor intensidade.

Figura 11 - Superfície de compensação de erro pelo método da Krigagem Oridinária

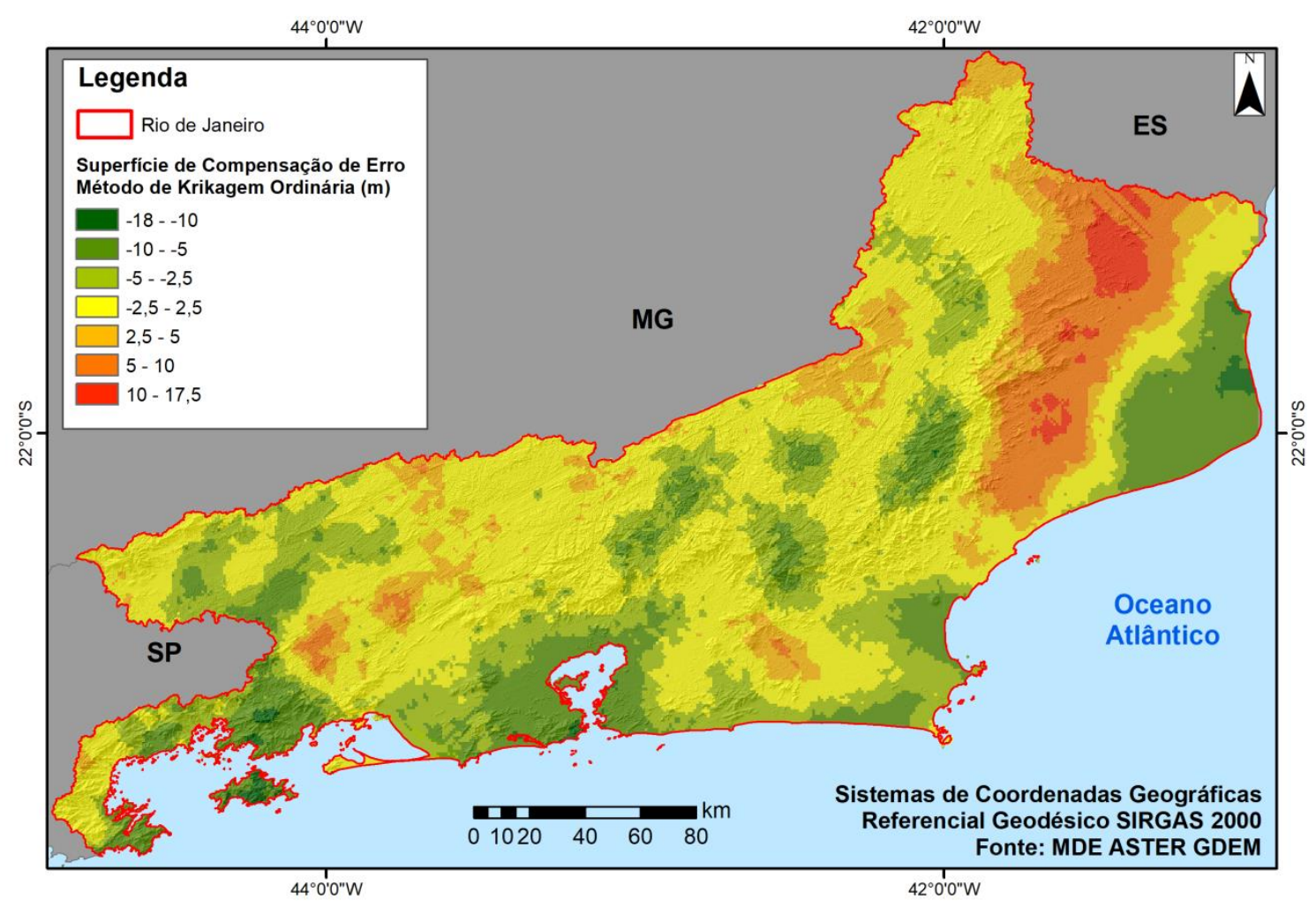

Fonte: Elaborada pelos autores.

A superfície de compensação de erro gerada pelo método da Krigagem Ordinária possui valores variando de $-14,14$ a 14,54, média de -0,87 e um desvio padrão de 4,40. A avaliação por validação cruzada obteve um EMQ de 5,70 e o gráfico de dispersão gerado pode ser observado na Figura 11. 
Figura 11 - Gráfico de dispersão da validação cruzada para a superfície de compensação de erro pelo método da Krigagem Oridinária

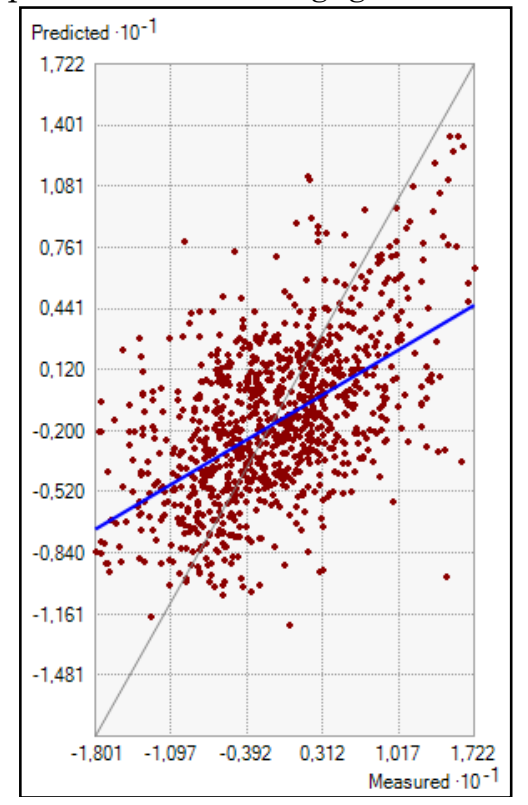

Fonte: Elaborada pelos autores.

A avaliação da acurácia vertical do MDE corrigido pelo método da Krigagem Ordinária com base na PEC-PCD obteve um EMQ de 5,93 e os resultados para a TV podem ser observados na Tabela 12. Dessa forma, o MDE ASTER GDEM corrigido pelo método de Krigagem Ordinária obteve, segundos os critérios da PEC-PCD, classe B para a escala 1:50.000 e classe A para as escalas 1:100.000 e 1:250.000.

Tabela 12 - Valores de TV do MDE ASTER GDEM corrigido pelo método da Krigagem Ordinária para as escalas 1:50.000, 1:100.000 e 1:250.000

\begin{tabular}{c|c|c|c}
\hline $\begin{array}{c}\text { Classe PEC- } \\
\text { PCD }\end{array}$ & $\mathbf{1 : 5 0 . 0 0 0}(\mathbf{\% )}$ & $\mathbf{1 : 1 0 0 . 0 0 0}(\mathbf{\% )}$ & $\mathbf{1 : 2 5 0 . 0 0 0 ~ ( \% )}$ \\
\hline A & 67,5 & 96,50 & 100,00 \\
\hline B & 90,25 & 100,00 & 100,00 \\
\hline C & 95,75 & 100,00 & 100,00 \\
\hline D & 97,5 & 100,00 & 100,00 \\
\hline- & 2,5 & 0,00 & 0,00 \\
\hline
\end{tabular}

Fonte: Elaborada pelos autores.

A Tabela 13 apresenta as estatísticas descritivas das diferenças relativas e absolutas entre os valores altimétricos do MDE ASTER GDEM corrigido pelo método da Krigagem Ordinária e os valores altimétricos dos Pontos de Controle para Avaliação correspondentes. 
Tabela 13 - Estatística descritiva das diferenças relativas e absolutas entre os valores altimétricos do MDE ASTER GDEM corrigido pelo método da Krigagem Ordinária e os Pontos de Controle para Avaliação correspondentes

\begin{tabular}{c|c|c}
\hline ASTER GDEM (KO) & Diferença Relativa & Diferença Absoluta \\
\hline Média & 0,33 & 4,48 \\
\hline Valor Mínimo & $-19,73$ & 0,04 \\
\hline Valor Máximo & 18,86 & 19,73 \\
\hline $\mathbf{1}^{\circ}$ Quartil & $-2,94$ & 1,52 \\
\hline Mediana & 0,50 & 3,33 \\
\hline $\mathbf{3}^{\circ}$ Quartil & 4,01 & 6,38 \\
\hline Desvio Padrão & 5,93 & 3,89 \\
\hline
\end{tabular}

Fonte: Elaborada pelos autores.

Assim como os métodos anteriores, o método da Krigagem Ordinária alcançou significativas melhoras na acurácia vertical do MDE ASTER GDEM para a área de estudo. No que se refere ao EMQ, teve uma melhora de 1,73 , reduzindo de 7,66 para 5,93, o que corresponde a uma diminuição de cerca de 22,6\%. Em relação à TV, destaca-se que os percentuais de pontos na classe A aumentaram em todas as escalas analisadas (1:50.000, 1:100.000 e 1:250.000), assim como os percentuais acumulados das classes B e C aumentaram nas escalas 1:50.000 e 1:100.000, o que fez o MDE corrigido pelo método de krigagem Ordinária alcançar a classe B da PEC-PCD para a escala 1:50.000.

As estatísticas descritivas das diferenças relativas e absolutas entre os valores altimétricos do MDE ASTER GDEM corrigido pelo método da Krigagem Ordinária e os Pontos de Controle para Avaliação correspondentes também registraram uma melhora significante do MDE corrigido para o MDE original. O valor médio das diferenças absolutas diminui de 5,82 para 4,46, os valores máximos também diminuíram de 31,84 para 19,73 e o desvio padrão das diferenças relativas e absolutas diminuíram, respectivamente, de 7,35 para 5,93 e de 4,76 para 3,89.

3.6 Comparação entre os métodos DVC, TIL, IDW e Krigagem Ordinária

As superfícies de compensação de erro obtidas pelos métodos DVC, TIL, IDW e Krigagem Ordinária foram eficientes na melhora da acurácia 
vertical do MDE ASTER GDEM. Contudo, é relevante destacar que alguns métodos foram mais eficientes do que outros. Portanto, a comparação dos resultados é uma etapa importante para avaliar quais métodos obtiveram maior sucesso.

O primeiro indicador a ser analisado é o resultado obtido na validação cruzada por cada método de interpolação utilizado na construção das superfícies de compensação de erro. Tal indicador não é aplicado ao método DVC, uma vez que o mesmo não consiste em um método de interpolação. $\mathrm{O}$ EMQ resultante da validade cruzada dos métodos TIL, IDW e Krigagem Ordinária (Tabela 14) evidenciam melhores resultados para o segundo e o terceiro, de forma que entre ambos a diferença é bem pequena.

Tabela 14 - EMQ resultante da validade cruzada dos métodos TIL, IDW e Krigagem Ordinária

\begin{tabular}{|c|c|}
\hline Superfície de Compensação de Erro & EMQ - Validação Cruzada \\
\hline TIL & 6,16 \\
\hline IDW & 5,76 \\
\hline Krigagem Ordinária & 5,70 \\
\hline
\end{tabular}

Fonte: Elaborada pelos autores.

Os parâmetros utilizados para avaliar a acurácia vertical dos MDEs com base na PEC-PCD também são importantes indicadores da eficiência das superfícies de compensação de erros elaboradas. No que se refere ao EMQ dos MDEs corrigidos (Tabela 15), o MDE corrigido pelo método DVC foi o que obteve a melhora menos significativa, de forma que os demais métodos obtiveram melhoras mais relevantes, principalmente o método da Krigagem Ordinária.

Tabela 15 - EMQ do MDE original e dos MDEs corrigidos

\begin{tabular}{c|c|}
\hline Superfície de Compensação de Erro & EMQ \\
\hline Original & 7,66 \\
\hline DVC & 7,29 \\
\hline TIL & 6,48 \\
\hline IDW & 6,04 \\
\hline Krigagem Ordinária & 5,93 \\
\hline
\end{tabular}

Fonte: Elaborada pelos autores. 
Em relação à TV (Tabela16), todos os métodos de correção dos MDEs apresentaram melhora nos resultados. Mais uma vez o método DVC foi o que obteve a melhora menos significativa, seguido dos métodos TIL, IDW e de Krigagem Ordinária. Salienta-se que o método de Krigagem Ordinária foi o único a obter percentual superior a 90\% para a classe B da escala 1:50.000, ainda que tenha obtido um percentual ligeiramente inferior ao método IDW para a classe A da mesma escala.

Tabela 16 - Valores de TV dos MDEs ASTER GDEM original e corrigidos para as escalas $1: 50.000,1: 100.000$ e $1: 250.000$

\begin{tabular}{|c|c|c|c|c|c|c|}
\hline \multirow[b]{2}{*}{$1: 50.000$} & \multirow{2}{*}{$\begin{array}{c}\text { Classe } \\
\text { PEC- } \\
\text { PCD }\end{array}$} & $\begin{array}{c}\text { MDE } \\
\text { Original }\end{array}$ & $\begin{array}{l}\text { MDE - } \\
\text { DVC }\end{array}$ & MDE - TIL & $\begin{array}{c}\text { MDE - } \\
\text { IDW }\end{array}$ & $\begin{array}{c}\text { MDE - } \\
\text { Krigagem } \\
\text { Ordinária }\end{array}$ \\
\hline & & $\begin{array}{c}\text { Pts de } \\
\text { Control. p/ } \\
\text { Avaliação } \\
(\%)\end{array}$ & $\begin{array}{c}\text { Pts de } \\
\text { Control. p/ } \\
\text { Avaliação } \\
(\%)\end{array}$ & $\begin{array}{c}\text { Pts de } \\
\text { Control. p/ } \\
\text { Avaliação } \\
(\%)\end{array}$ & $\begin{array}{c}\text { Pts de } \\
\text { Control. p/ } \\
\text { Avaliação } \\
(\%)\end{array}$ & $\begin{array}{c}\text { Pts de } \\
\text { Control. p/ } \\
\text { Avaliação } \\
(\%)\end{array}$ \\
\hline $0-5,5 \mathrm{~m}$ & A & 56,18 & 61,78 & 66,75 & 69.00 & 67,5 \\
\hline $0-10 \mathrm{~m}$ & B & 84,13 & 85,60 & 87,40 & 89,50 & 90,25 \\
\hline $0-12 \mathrm{~m}$ & $\mathbf{C}$ & 89,48 & 88,58 & 91,93 & 94,75 & 95,75 \\
\hline $0-15 \mathrm{~m}$ & D & 94,79 & 93,79 & 97,97 & 97,25 & 97,5 \\
\hline$>15 \mathrm{~m}$ & & 5,21 & 6,21 & 2,03 & 2,75 & 2,50 \\
\hline $1: 100.000$ & $\begin{array}{c}\text { Classe } \\
\text { PEC- } \\
\text { PCD }\end{array}$ & $\begin{array}{c}\text { Pts de } \\
\text { Control. p/ } \\
\text { Avaliação } \\
(\%) \\
\end{array}$ & $\begin{array}{c}\text { Pts de } \\
\text { Control. p/ } \\
\text { Avaliação } \\
(\%) \\
\end{array}$ & $\begin{array}{c}\text { Pts de } \\
\text { Control. p/ } \\
\text { Avaliação } \\
(\%) \\
\end{array}$ & $\begin{array}{c}\text { Pts de } \\
\text { Control. p/ } \\
\text { Avaliação } \\
(\%) \\
\end{array}$ & $\begin{array}{c}\text { Pts de } \\
\text { Control. p/ } \\
\text { Avaliação } \\
(\%) \\
\end{array}$ \\
\hline $0-13,7 \mathrm{~m}$ & A & 92,30 & 92,55 & \begin{tabular}{|l|}
95,72 \\
\end{tabular} & 96,25 & 96,5 \\
\hline $0-25 \mathrm{~m}$ & B & 99,74 & 99,75 & 100 & 100 & 100 \\
\hline $0-30 \mathrm{~m}$ & $\mathbf{C}$ & 99,98 & 100 & 100 & 100 & 100 \\
\hline $0-37,5 \mathrm{~m}$ & $\mathbf{D}$ & 100 & 100 & 100 & 100 & 100 \\
\hline$>37,5 \mathrm{~m}$ & & 0 & 0 & 0 & 0 & 0 \\
\hline $1: 250.000$ & $\begin{array}{c}\text { Classe } \\
\text { PEC- } \\
\text { PCD }\end{array}$ & $\begin{array}{c}\text { Pts de } \\
\text { Control. p/ } \\
\text { Avaliação } \\
(\%) \\
\end{array}$ & $\begin{array}{c}\text { Pts de } \\
\text { Control. p/ } \\
\text { Avaliação } \\
(\%) \\
\end{array}$ & $\begin{array}{c}\text { Pts de } \\
\text { Control. p/ } \\
\text { Avaliação } \\
(\%) \\
\end{array}$ & $\begin{array}{c}\text { Pts de } \\
\text { Control. p/ } \\
\text { Avaliação } \\
(\%) \\
\end{array}$ & $\begin{array}{c}\text { Pts de } \\
\text { Control. p/ } \\
\text { Avaliação } \\
(\%) \\
\end{array}$ \\
\hline $0-27 \mathrm{~m}$ & A & 99,72 & 100 & 100 & 100 & 100 \\
\hline $0-50 \mathrm{~m}$ & B & 100 & 100 & 100 & 100 & 100 \\
\hline $0-60 \mathrm{~m}$ & $\mathbf{C}$ & 100 & 100 & 100 & 100 & 100 \\
\hline $0-75 \mathrm{~m}$ & $\mathbf{D}$ & 100 & 100 & 100 & 100 & 100 \\
\hline$>75 \mathrm{~m}$ & & 0 & 0 & 0 & 0 & 0 \\
\hline
\end{tabular}

Fonte: Elaborada pelos autores.

Para as escalas 1:100.000 e 1:250.000, o MDEs originais e corrigidos obtiveram classe A da PEC-PCD. Porém para a escala 1:50.000, o MDE 
original e o MDE corrigido pelo método DVC obteve classe D da PEC-PCD, os MDEs corrigidos pelos métodos TIL e IDW obteve classe C e o MDE corrigido pelo método de Krigagem Ordinária obteve classe B.

\section{Considerações Finais}

A utilização das superfícies de compensação de erro foi eficiente no aumento da acurácia vertical do MDE ASTER GDEM original. Portanto, a metodologia empregada nesse estudo pode ser uma relevante alternativa para a melhora da acurácia vertical de MDEs, principalmente quando não se conhece detalhadamente a natureza e magnitude das fontes de erro dos mesmos. Contudo, vale destacar que é necessária uma amostragem adequada dos pontos de campo com informações de altitude levantadas com alta precisão.

O DVC foi o método mais simples, exigindo um menor custo computacional e um menor esforço geral para sua elaboração, porém também é o método mais limitado, uma vez que não leva em consideração a variação espacial não uniforme dos erros pela área de estudo. Dessa forma, o DVC foi o método que obteve a menor melhora da acurácia vertical do MDE.

O TIL, um dos métodos que empregou interpolação determinística, gerou uma superfície de compensação de erro com menor suavização, tendo transições mais abruptas que as demais superfícies de compensação de erro. O método TIL obteve uma melhora bem significativa da acurácia vertical do MDE ASTER GDEM original, alcançando, inclusive, a classe C para a escala 1:50.000 na PEC-PCD.

O IDW foi método, dos que empregaram interpolação determinística, que apresentou melhor desempenho na melhora da acurácia vertical do MDE ASTER GDEM original, contudo, assim como o método TIL, o MDE corrigido pelo método IDW alcançou a mesma classe $\mathrm{C}$ para a escala 1:50.000 na PEC-PCD. Vale destacar, que o método IDW gerou a superfície de compensação de erro mais suave dentre os métodos empregados. 
A Krigagem Ordinária, único método que empregou interpolação geoestatística, foi a que obteve os melhores resultados na melhora da acurácia vertical do MDE ASTER GDEM original, sendo o único método a alcançar a classe B para a escala 1:50.000 na PEC-PCD. Contudo, a Krigagem Ordinária também foi o método que exigiu maior esforço geral, necessitando mais procedimentos e processamentos para o seu desenvolvimento.

Para estudos futuros, é sugerida uma avaliação da influência da quantidade e espacialização do conjunto amostral na elaboração das superfícies de compensação de erro e no desempenho das mesmas na melhora da acurácia vertical de MDEs. Também é recomendada a avaliação de demais métodos geoestatísticos não utilizados nesse estudo.

A influência da não compatibilização entre os datuns verticais WGS84 (EGM96) e Imbituba (MAPGEO15) no resultado das correções do MDE original é outra questão a ser melhor investigada em estudos futuros.

\section{Contribuição dos autores}

Raphael e Silva Girão, como autor principal, foi o idealizador do tema do artigo, sendo responsável por sua escrita, pela pesquisa bibliográfica, pelos processamentos dos dados e análise dos resultados.

Raúl Sánchez Vicens orientou e contribuiu no processamento de dados, principalmente no que se refere à krigagem ordinária, e na análise dos resultados.

Pedro José Farias Fernandes contribuiu no desenvolvimento dos algoritmos em $R$ utilizados nas interpolações e na avaliação dos MDEs originais e corrigidos. 


\section{Referências}

ANDERS, N. S.; SEIJMONSBERGEN, A. C.; BOUTTEN, W. Segmentation optimization and stratified object-based analysis for semi-automated geomorphological mapping. Remote Sensing of Environment, vol. 115, n. 12, 2011. pp. 2976-2985.

ASSELEN, S.; SEIJMONSBERGEN, A. C. Expert-driven semi-automated geomorphological mapping for a mountainous area using a laser DTM. Geomorphology, vol. 78, n. 3.4, 2006. pp. 309-320.

AUDETTE, M. A.; FERRIE, F. P.; PETERS, T. M. An algorithmic overview of surface registration techniques for medical imaging, Medical Image Analysis, vol 2, 2000. pp. 201-217.

BARROS, R. S. Avaliação da Altimetria de Modelos Digitais de Elevação Obtidos a partir de Sensores Orbitais. Tese de doutoramento. Universidade Federal do Rio de Janeiro, Programa de Pós-Graduação em Geografia, Rio de Janeiro, 2006. 195p.

BLASCHKE, T. Object based image analysis for remote sensing. ISPSR Journal of Photogrammetry and Remote Sensing, vol. 65, n. 1, 2010. pp. 2-16.

BRASIL. Especificação Técnica para a Aquisição de Dados Geoespaciais Vetoriais (ET-ADGV) Versão 2.1.3. Diretoria de Serviço Geográfico do Exército Brasileiro. 2011.

BURROUGH, P.; MCDONNELL, R. Principles of geographical Information Systems. Oxford: Clarendon, 1998. 333p.

CÂMARA, G.; DAVIS, C.; MONTEIRO, A. M. V. Introdução à ciência da geoinformação. São José dos Campos: INPE, 2001. 344 p.

CAMARGO, E. C. G. Geoestatística: Fundamento e Aplicações. In: CAMARA, G.(ed.); MEDEIROS, J. S. (ed.). Geoprocessamento em Projetos Ambientais. $2^{a}$ ed. São José dos Campos: INPE, 1998. pp. 15-36.

CAMARGO, E. C. G.; FUCKS, S. D.; CÂMARA, G. Análise Espacial de Superfícies por Geoestatística Espacial. In: Análise Espacial de Dados Geográficos. Brasília: EMBRAPA. 2004. pp. 1-37. 
CARVALHO, T. M.; LATRUBESSE, E. M. Aplicação de modelos digitais do terreno (MDT) em análises macrogeomorfológicas: o caso da bacia hidrográfica do Araguaia. Revista Brasileira de Geomorfologia, vol. 5, pp. 85-93, 2004.

DRAGUT, L.; EISANK, C. Automated object-based classification of topography from SRTM data. Geomorphology, vol. 141-142, n. 1, 2012. pp. 21-33.

EBNER, H.; MUELLER, F. Processing of digital three line imagery using a generalized model for combined point determination. Int. Archives of Photogrammetry and Remote Sensing, vol. 26, n. 3/1, 1986. pp. 212-222.

EBNER, H.; STRUNZ, G. Combined point determination using Digital Terrain Models as control information. Int. Archives of Photogrammetry and Remote Sensing, vol. 27, n. B11/3, 1988. pp. 578-587.

ELMIRO, M. A. T.; DUTRA, L. V.; MURA, J. C. Altimetry fitting methods for INSAR digital elevation models. Revista Brasileira de Cartografia, vol. 60, 2008. pp.263-269.

EL-SHEIMY, N.; VALEO, C.; HABIB, A. Digital Terrain Modeling: Acquisition, Manipulation, and Applications. Boston/EUA. Artech House. 2005. 270p.

ERXLEBEN, J.; ELDER, K.; DAVIS, R. Comparison of spatial interpolation methods for estimating snow distribution in the Colorado Rocky Mountains. Hydrological Processes, vol. 16(18), 2002. pp. 3627-3649.

ENVIRONMENTAL SYSTEMS RESEACH INSRITUTE. ArcGis, versão 10.3, 2016.

FAN, L.; POWRIE, W.; SMETHURST, J.; ATKINSON, P.M.; EINSTEIN, A.N.D.H. The effect of short ground vegetation on terrestrial laser scans at a local scale. ISPRS J. Photogramm. Remote Sens, vol. 95, 2014. pp, 42-52.

FERNANDEZ, A.; ADAMOWSKI, J. PETROSELLI, A. Analysis of the behavior of three digital elevation model correction methods on critical natural scenarios. Journal of Hydrology: Regional Studies, vol. 8, 2016. pp. 304-315.

FRANKEL, K. L.; DOLAN, J. F. Characterizing arid region alluvial fan surface roughness with airborne laser swath mapping digital topographic data. J. Geophys, vol. 112, 2007. 
GRUEN, A. Adaptive least squares correlation: a powerful image matching technique. South African Journal of Photogrammetry, Remote Sensing and Cartography, vol.14, n. 3, 1985. pp. 175-187.

GRUEN, A.; AKCA, D. Least squares 3D surface matching, Anais...ASPRS 2005 Annual Conference, Baltimore, Maryland, 2005. pp. 7-11.

GUIMARÃES, E. C. Geoestatística Básica e Aplicada. UFU/FAMAT, Núcleo de estudos estatísticos e Biométricos, 2004. 74p.

JOHNSON, A. E.; KANG, S. B. Registration and integration of textured 3D data. Image and Vision Computing, vol. 17, n. 2, 1999. pp. 135-147.

LI, Z.; ZHU, Q.; GOLD, C. Digital Terrain Modeling: Principles and Methodology. London/UK. Taylor \& Francis, 2004. 324p.

LILLESAND, T. M.; KIEFER, R. W.; CHIPMAN, J. W. Remote Sensing and Image Interpretation. Nova Iorque/EUA. John Wiley \& Sons, 2007. 756p.

LINDSAY, J. B.; EVANS, M. G. The influence of elevation error on the morphometrics of channel networks extracted from DEMs and the implications for hydrological modelling. Hydrological Processes. vol. 22, 2008. pp. 1588-1603.

MAAS, H. G. Least-Squares Matching with airborne laserscanning data in a TIN structure. Int. Archives of Photogrammetry and Remote Sensing, vol.33, n. 3A, 2000. pp. 548-555.

MAAS, H. G. On the use of pulse reflectance data for laserscanner strip adjustment. Int. Archives of Photogrammetry and Remote Sensing, vol. 34, n. 3/W4, 2001.

MARCUZZO, F. F. N.; ANDRADE, L. R.; MELO, D. C. R. Métodos de Interpolação Matemática no Mapeamento de Chuvas do Estado do Mato Grosso. Revista Brasileira de Geografia Física, vol. 4, 2011. pp. 793-804.

MOURA, P. Calibração dos modelos digitais de elevação gerados por interferometria SAR nas bandas PEX. Dissertação de Mestrado Instituto Nacional de Pesquisas Espaciais, São José dos Campos. 2005.

MUÑOZ, J. D.; KRAVCHENKO, A. Deriving the optimal scale for relating topographic attributes and cover crop plant biomass. Geomorphology, vol 179, 2012. pp. 197-207. 
MUKHERJEE, S. J. P.; MUKHERJEE, S.; GHOSH, A.; GARG, R.; MUKHOPADHYAY, A. Evaluation of vertical accuracy of open source Digital Elevation Model (DEM). International Journal of Applied Earth Observation and Geoinformation, vol. 21, 2013. pp. 205-217.

NOURANI, V.; ZANARDO, S. Wavelet-based regularization of the extracted topographic index from high-resolution topography for hydrogeomorphicapplications. Hydrol. Processes, vol. 28, n. 3, 2014. pp. 13451357.

PATEL, A.; KATIYAR, S. K.; PRASAD, V. Performances evaluation of different open source DEM using Differential Global Positioning System (DGPS). Egypt J. Remote Sens. Space Sci, vol. 19, 2016. pp. 7-16.

PETROSELli, A.; VESSELlA, F.; CAVAGNUOLO, L.; PIOVESAN, G.; SCHIRONE, B. Ecological behaviour of Quercus suber and Quercus ilex inferred by topographicwetness index (TWI). Trees Struct, vol. 27, n. 5, 2013. pp. 1201-1215.

PETROSELLI, A.; LEONE, A.; RIPA, M.N.; RECANATESI, F. Linking phosphorus export and hydrologic modelling: a case study in central Italy. Environ. Monit, vol. 186, 2014. pp. 7849-7861.

RICCOMINI, C. O Rift Continental do Sudeste do Brasil. Tese de doutoramento. Universidade de São Paulo, São Paulo, 1989. 256 p.

RICCOMINI, C. Tectonismo gerador e reformador dos depósitos sedimentares Pós-Gondwânicos da porção centro-ocidental do Estado de São Paulo e áreas vizinhas. Tese de livre docência. Universidade de São Paulo, São Paulo. 1995. 198p.

ROSENHOLM, D.; TORLEGARD, K. Three-dimensional absolute orientation of stereomodels using Digital Elevation Models. Photogrammetric Engineering \& Remote Sensing, vol. 54, n. 10, 1988. pp. 1385-1389.

RSTUDIO TEAM. RStudio: Integrated development for R. RStudio, Inc., Boston, MA. 2015.

SANTANA, R. A.; SANTOS, N. T. Utilização de técnicas geoestatística na otimização de amostragem em parcelas de povoamentos de Tectona Grandis. Anais do XIX Simpósio Nacional de Probabilidade Estatística. 2010. pp. 1-6. 
SANTOS, A. P. Avaliação da Acurácia Posicional em Dados Espaciais com o uso da Estatística Espacial. Dissertação de mestrado. Universidade Federal de Viçosa, Viçosa, 2010. 128p.

SHEWCHUK, J. R. Lecture notes on Delaunay mesh generation. Berkeley, CA: Department of Electrical and Computer Science, University of California at Berkeley, 1999.

SILVA, T. M. A Estruturação Geomorfológica do Planalto Atlântico no Estado do Rio de Janeiro. Tese de doutoramento. Universidade Federal do Rio de Janeiro, Programa de Pós-Graduação em Geografia, Rio de Janeiro, 2002 .

SU, Y.; GUO, Q. A pratical method for SRTM DEM correction over vegetated mountain areas. ISPRS Journal of Photogrammetry and Remote Sensing, vol. 87, 2014. pp. 216-228.

SU, Y.; GUO, Q.; MA, Q; LI, W. SRTM DEM Correction in Vegetated Mountain Areas through the Integration of Spaceborne LiDAR, Airborne LiDAR, and Optical Imagery. Remote Sensing, vol. 7, 2015.

TANG, G.; HUI, Y.; STROBL, J.; LIU, W. The impact of resolution on the accuracy of hydrologic data derived from DEMs. Journal of Geographical Sciences, vol. 11, 2001. pp. 393-401.

TOUTIN, T. RADARSAT-2 stereoscopy and polarimetry for 3D mapping. Canadian Journal of Remote Sensing, vol. 30, n. 3. 2004. pp. 496-503.

VANDEN WYNGAERD, J.; Van GOOL, L. Combining texture and shape for automaticcrude patch registration. Anais do IEEE INT. CONFERENCE ON 3D DIGITAL IMAGING AND MODELING, Banff, Canada, 2003. pp. 179-186.

VERHAGEN, P.; DRAGUT, L. Object-based landform delineation and classification from DEMs for achaeological predictive mapping. Journal of Archaelogical Science, vol. 39, n. 3, 2012. pp. 608-703.

VIEIRA, S. R. Geoestatística em estudos de variabilidade espacial do solo. In. NOVAES, R. F. (ed.); ALVAREZ V., V. H. (ed.); SCHAEFER, C. E G. R. (ed.); Tópicos em ciências do solo. Sociedade Brasileira de Ciência do Solo, Viçosa (MG), 2000. pp. 2-54. 
VILELA, L. C. Comparação entre as redes neurais artificiais e o método de interpolação krigagem aplicados à pesquisa agronômica. Tese de doutoramento. UNESP. Botucatu, 2004. 124p.

WANDERLEY, H. S.; AMORIM, R. F. C.; CARVALHO, F. O. Variabilidade Espacial e Preenchimento de falhas de dados pluviométricos para o estado de Alagoas. Revista Brasileira de Meteorologia, vol.27, 2012. pp. 347-354.

WECHSLER, S. P. Uncertainties associated with digital elevation models for hydrologic applications: a review. Hydrology and Earth System Sciences, vol. 11, 2007. pp. 1481-1500.

WILSON, J. P.; GALLANT, J. C. Digital terrain analysis. In: Terrain analysis: principles and applications, New York: Wiley, 2000. pp. 29-49.

WILSON, J. P. Digital terrain modeling. Geomorphology, vol. 137, 2012. pp. 107121.

XU, Z.; LI, Z. Least median of squares matching for automated detection of surface deformations. Int.Archives of Photogrammetry and Remote Sensing, vol. 33, n. B3, 2000. pp.1000-1007.

YAMAMOTO, J.K.; LANDIM, P.M.B. Geoestatística: conceitos e aplicações. São Paulo: Oficina de Textos, 2013. 215p. 